\title{
Measuring and Assessing Road Profile by Employing Accelerometers and IRI Assessment Tools
}

\author{
Sulaymon Eshkabilov*, Abduvokhid Yunusov \\ Dynamics \& Control Lab, Tashkent Institute of Automotive Road Design, Construction and Maintenance, Tashkent, Uzbekistan
}

Email address:

sulaymon@d-c-lab.com(S. Eshkabilov), abduvokhid@engineering.uz(A. Yunusov)

*Corresponding author

\section{To cite this article:}

Sulaymon Eshkabilov, Abduvokhid Yunusov. Measuring and Assessing Road Profile by Employing Accelerometers and IRI Assessment Tools. American Journal of Traffic and Transportation Engineering. Vol. 3, No. 2, 2018, pp. 24-10. doi: 10.11648/j.ajtte.20180302.12

Received: March 26, 2018; Accepted: April 10, 2018; Published: May 11, 2018

\begin{abstract}
This paper presents experimental studies from the road profile measurements by employing accelerometers and international roughness index - IRI assessment tools and practical guidelines with respect to measured acceleration data processing in terms of digital filter design and conversion of vertical acceleration data into displacement data. In addition, it shows comparative analysis of measurements with accelerometers and Rod \& Level (Leica TS 06 Plus), and gives some recommendations how to process measured data.
\end{abstract}

Keywords: Road Profile, Digital Filter, Integration, Acceleration, Accelerometer, IRI

\section{Introduction}

It is a well-known fact that roads are one of the most vital sectors of economy of any nations. Therefore, it is proved that by improving roads, quality of goods and passengers transportation will be improved. For this purpose, it is salient to assess a quality level of road construction and periodic diagnostics of road profiles in order to keep sufficient quality of the road pavement and assess necessary assets for repairing and maintenance of roads. There are a few different methods and tools to evaluate and characterize road roughness and the longitudinal evenness of a road. One of them is the measuring dynamic effects of the road on a car (suspension - axle - un-sprung mass and/or car body-sprung mass) by employing different measuring devices such as, accelerometers, velocity or displacement gauges or high speed laser/infrared/ultrasonic sensing devices to measure vertical irregularities of road surface. The other one is to measure the geometrical parameters of the pavement by using high precision measuring and surveying systems. Subsequently, one evaluates the power spectral density (PSD) of the longitudinal elevation of the road profile. All of these approaches have some pros and cons with respect to each other in terms of precision, accuracy, efficiency, application purpose and cost. The whole issue of profile measurement and assessment requires two key aspects, which are data/signal processing and hardware (measurement devices and tools) issues. The measured data of the road profile can be evaluated by using international roughness index - IRI [1] and ISO 8608 [2] standards and national or regional standards some of them are based on the International Standards. In many studies dedicated to the road profile measurements, vehicle-road interaction is used as a main approach. Besides, these standardized methodologies, there are a few other techniques used in practice. All of the assessment tools and their indices are cost related.

In this paper, some practical aspects of the vibration response type of longitudinal road profile measurement by using single axis accelerometers installed on the front axle and car body are highlighted. Some emphases on correlations of the IRI assessments of the response type approach and geometry based approach measuring pavement irregularities are made. Moreover, some recommendations how to process measured data by employing digital signal filters and comparative analysis of terrain measurement tools are underlined. In these studies, a vehicle-road interaction approach to measure experimentally and evaluate longitudinal unevenness and assess it via a quarter car model of the IRI in numerical simulations is used. 


\section{Literature Review}

In many theoretical and experimental studies of a response type of approach, in evaluating road pavement irregularities, a quarter car model [3-6] is taken into consideration to model the vehicle-road system. Various speeds from 20 to $100 \mathrm{~km} / \mathrm{h}$ are chosen to drive a vehicle on the road subject for studies and the measurement results are assessed with respect to the IRI [1]. It should be noted that the IRI is widely adopted as a main assessment tool or reference tool for evaluating longitudinal road profiles in many nations around the globe in order to obtain preliminary calculations and assessments of road diagnostics, maintenance costs and quality of newly constructed roads. The quarter car model approach type - IRI is widely used and adapted. Apart for the quarter car model approach, half car roughness index [7], full car roughness index [8] and the ride number [9] approaches are also developed and studied. There are several advantages of the quarter car - IRI approach. This method is simple and easy to use, fast and cost efficient in evaluations.

Some early theoretical studies on road profiles are dedicated on modeling road profile irregularities by Gaussian processes [10]. In fact, road profile irregularities cannot be completely a Gaussian type of noise signal and thus, such modeling approach is not sufficiently accurate. Thus, a few other approaches have been proposed to model random processes of terrain profiles and speed bumps, for instance, Laplace transforms [3, 11-13]. By this approach, changing variances of road irregularities are attained randomly. There is another formulation in this respect that describes road profile as a series of sinusoid waves [14].

In addition to the above-mentioned approaches, in assessing longitudinal evenness of the road profile, another technique considering the weighted longitudinal profile [15] is proposed. One of the key advantages of this method is that it encompasses key features of the existing response type of method along with the geometrical approaches. In recent studies [16], 3D assessments of the pavements along with the $3 \mathrm{D}$ vehicle models are proposed. In these studies, by employing road mapping equipment, 3D shape of the pavements is taken that has a few solid advantages over 1D/2D road pavement models, but this approach requires considerably expensive rotating laser sensors.

According to [17], measuring techniques of the surface roughness of road profiles are grouped into four classes based on how directly the measured data correspond to the IRI measures. From the poorest to the highest quality/accuracy, Class 4 - Visual Inspection; Class 3 Response Type of Roughness measures; Class 2 - Profile based approach (laser profile-meters); Class 1 - Profile based approach (Rod and Level Dipstick) similar to Class 2. In most of the cases, the task in measuring longitudinal road roughness is to obtain relatively high quality of measurements with convenient and less expensive devices. Therefore, measurements with Class 3 type of approach it is aimed to go up to the level of Class 2 in terms of accuracy.

The response type of longitudinal road profile measurements under Class 3, the acceleration data recorded from accelerometers (for instance). Numerically, vertical displacement values from the acceleration by double integration or using Fourier Transforms and their inverse can be computed. In both of these approaches, different filtering techniques (IIR, FIR, Chebyshev, Butterworth, Moving Average) in order to remove undesired noises from the measured acceleration data are used. One of the challenging issues in this approach is, while computing road profile (vertical displacement of vehicle's axle and body) from the measured acceleration data from accelerometers how to perform numerical integration, choose appropriate digital filters, and tune them.

\section{Mathematical Formulations}

A quarter car model with Golden Car parameters as specified in the IRI to assess the measured data from the inertial sensing devices (accelerometers) is considered. In addition, it is considered that a tire has small or no damping effect. With these preconditions, the next physical model (Figure 1) of the system for passive system of a quarter-car model is drawn.

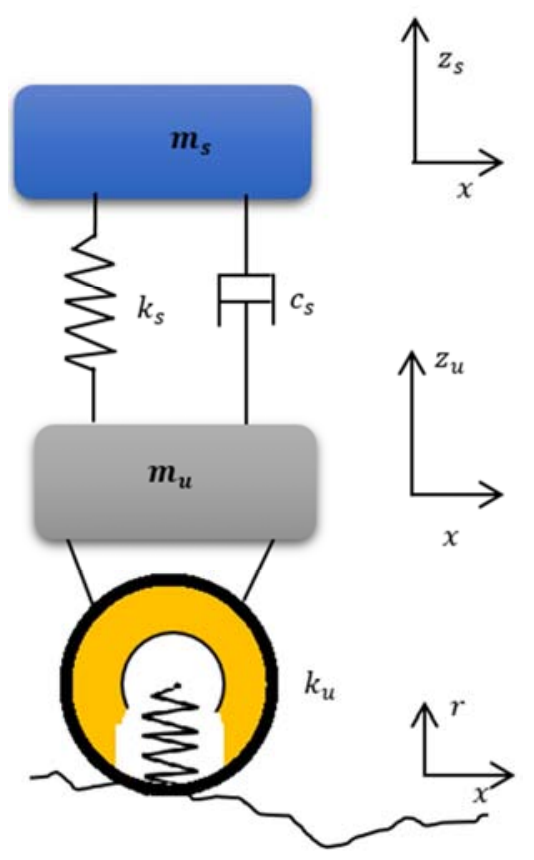

Figure 1. Quarter-car model according to the IRI [1].

From the quarter-car model shown in Figure 1, the equations of motion of the two mass bodies, which are unsprung mass (half of axle mass and one wheel) $m_{u}$ and sprung mass (quarter car body mass) $m_{s}$ are derived. The equations of motion of the system (Figure 1) are the followings (1).

$$
\left\{\begin{array}{c}
m_{s} \ddot{z}_{s}+c_{s}\left(\dot{z}_{s}-\dot{z}_{u}\right)+k_{s}\left(z_{s}-z_{u}\right)=0 \\
m_{u} \ddot{z}_{u}+c_{s}\left(\dot{z}_{u}-\dot{z}_{s}\right)+k_{s}\left(z_{u}-z_{s}\right)+k_{u} z_{u}=k_{u} r
\end{array}\right.
$$

Where $z_{s}, \dot{z}_{s}$ and $\ddot{z}_{s}$ are displacement, velocity and 
acceleration of the sprung mass (quarter car body mass), respectively; $z_{u}, \dot{z}_{u}$ and $\ddot{z}_{u}$ are displacement, velocity and acceleration of the un-sprung mass (half of axle mass and one wheel), respectively; $c_{s}$ damping coefficients of suspension; $k_{s}$ and $k_{u}$ stiffness of suspension and tire; $m_{s}$ and $m_{u}$ are masses of the sprung (quarter car) and un-sprung (axle + tire); $r$ is terrain roughness (road irregularities) dependent of a vehicle's speed on the $x$ direction. The values of the two displacements are computed by employing numerical integration methods such as Simpson's, trapezoidal and Newmark- $\beta$ method [18] as expressed in (2), (3) and (4). The vehicle is moving on the direction of $x$-axis as depicted in Figure 1.

$$
\begin{gathered}
\left\{\begin{array}{l}
\dot{z}_{i+1}=\dot{z}_{i}+\frac{\left(\ddot{z}_{i}+4 \ddot{z}_{i+1}+\ddot{z}_{i+2}\right) \Delta t}{6} \\
z_{i+1}=z_{i}+\frac{\left(\dot{z}_{i}+4 \dot{z}_{i+1}+\dot{z}_{i+2}\right) \Delta t}{6} \text { for } i \geq 1,
\end{array}\right. \\
\left\{\begin{array}{l}
\dot{z}_{i+1}=\dot{z}_{i}+\frac{\left(\ddot{z}_{i}+\ddot{z}_{i+1}\right)}{2 f_{S}} \\
z_{i+1}=z_{i}+\frac{\dot{z}_{i}+\dot{z}_{i+1}}{2 f_{s}} \text { for } i \geq 1,
\end{array}\right. \\
\left\{\begin{array}{c}
\dot{z}_{i+1}=\dot{z}_{i}+\left(\ddot{z}_{i}+\ddot{z}_{i+1}\right) \frac{\Delta t}{2} \\
z_{i+1}=z_{i}+\Delta t \dot{z}_{i}+\frac{1-2 \beta}{2} \Delta t^{2} \ddot{z}_{i}+\beta \Delta t \ddot{z}_{i+1}
\end{array} \text { for } i \geq 1,\right.
\end{gathered}
$$

Where $z_{i}, \dot{z}_{i}$ are vertical displacement and velocity computed from the measured acceleration $\left(\ddot{z}_{i}\right)$ responses of the un-sprung (axle) and sprung (car body) masses. For the Newmark- $\beta$ method, a typical value for $\beta=0.50$ is taken. For the IRI calculations, the quantities of $z_{u}$ un-sprung mass displacement computed numerically by double integration according to (2), (3), (4) and Fourier and inverse Fourier Transforms are used. The road profile roughness $r$ in the expression (1), can be computed from (5) with respect to values of two displacements $z_{u}, z_{s}$.

$$
r=\frac{m_{u}}{k_{u}} \ddot{z}_{u}+\frac{c_{s}}{k_{u}}\left(\dot{z}_{u}-\dot{z}_{s}\right)+\frac{k_{s}}{k_{u}}\left(z_{u}-z_{s}\right)+z_{u}
$$

It should be noted that the ratios the constant values in (5), $\frac{m_{u}}{k_{u}}, \frac{c_{s}}{k_{u}}, \frac{k_{s}}{k_{u}}$ are relatively small values and thus, the acceleration, velocity values of the sprung and un-sprung masses, and can take only displacement of the un-sprung mass only to compute road profile numerically for further analysis with the IRI are neglected. Subsequently, the IRI [1] values are computed numerically from (6) based on the values of the road profile roughness $r$, and evaluates $Z_{S}$ and $z_{u}$ of the axle and car body according to the Golden Car [19, 20] parameters, i.e. $m_{s}, m_{u}, c_{s}, k_{s}, k_{u}$.

$$
I R I=\frac{1}{n} \sum_{i=1}^{n}\left|\dot{z}_{s, i}-\dot{z}_{u, i}\right|
$$

The variables $z_{s}, z_{u}$ are recomputed using the values of the variables $\dot{z}_{s, i}$ and $\dot{z}_{u, i}$ that are velocity values of the sprung and un-sprung masses.

\section{Experiment and Simulation Results}

The experimental studies are composed of three different measurements to identify accuracy two different response type of measurements, viz. high precision single axis accelerometers from Dytran ${ }^{\mathrm{TM}}$ and Roughometer III developed by ARRB group Ltd against reference measurements from Total Station 06 of Leica Geo-System ${ }^{\mathrm{TM}}$. At first, $100 \mathrm{~m}$ long asphalt pavement road is selected and its surface profile is measured on the 400 equally spaced mark points with Total Station 06. Then on the same selected road two response type measurements are carried out according to the generalized test procedures shown in Figure 2. All of the measured data are analyzed according to the generalized data analysis procedures as demonstrated in Figure 3.

For the measurement tests, reference measurements of the road profile are taken in each marked point from Total Station 06 of Leica Geo-System ${ }^{\mathrm{TM}}$ (Figure 4) and all measurements are performed according to the ASTM Standard E1364-95 [21]. These measurement data points with a sampling frequency of $0.25 \mathrm{~m}$ per $1 \mathrm{~m}$ are considered to be a main reference for quality checks of the data from the other two response type of measurements for the IRI assessment calculations with the Golden Car parameters.

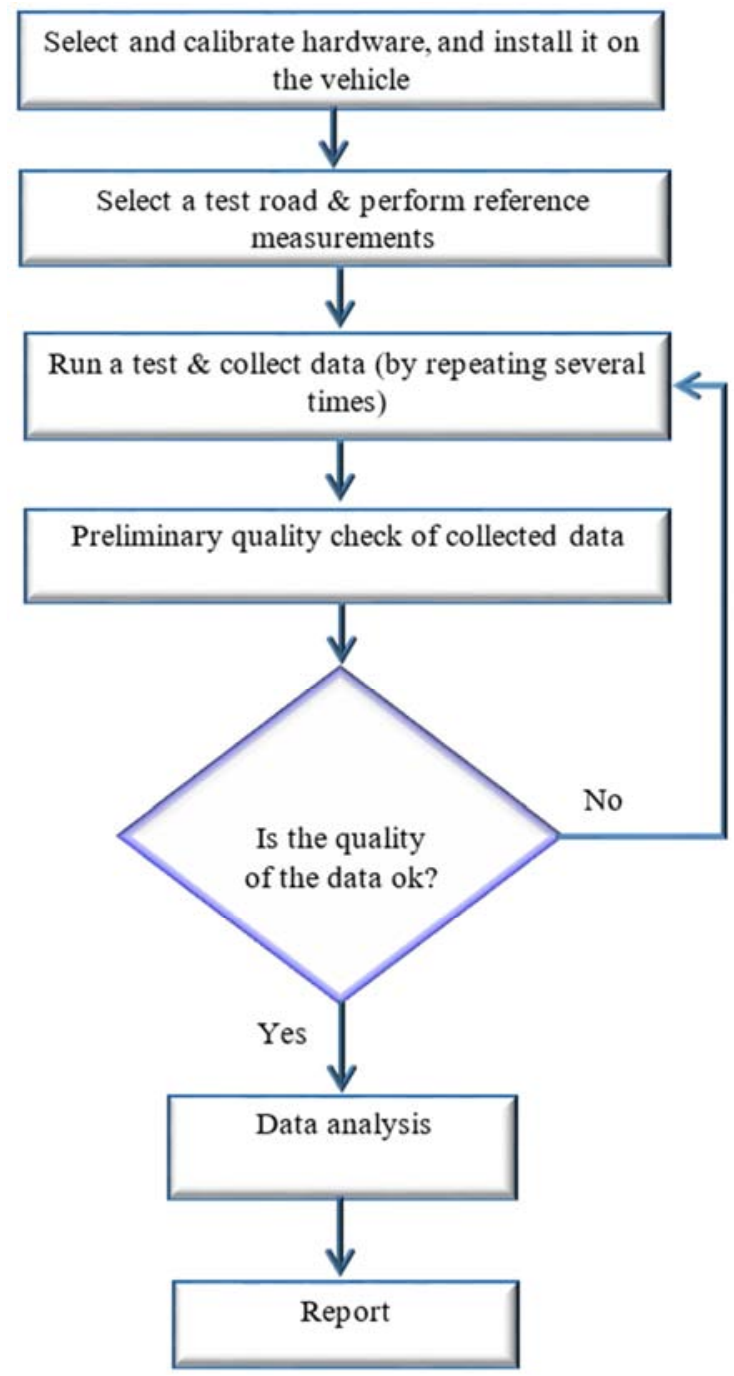

Figure 2. Generalized test procedures. 
The single axis accelerometers from Dytran ${ }^{\mathrm{TM}}$ are installed on the right and left sides of the front axle, and car body (frame) of the vehicle (Figure 5). The measured data is collected via AD Converter DAQ - DT9838 from DATATRANSLATION $^{\circledR}$ and laptop computer (Figure 6). For tests a medium size sedan type of vehicle with good technical conditions is used for response type measurements and utilized three single axis accelerometers from Dytran ${ }^{\mathrm{TM}}$ with 10 gram of weight and reference sensitivity of $10.1,10.2$, and $10.3 \mathrm{mV} / \mathrm{g}\left(g=\frac{9.81 \mathrm{~m}}{\mathrm{~s}^{2}}\right)$. The accelerometers are attached with magnetic pads (Figure 5) onto the two sides of the front axle and car body (frame).

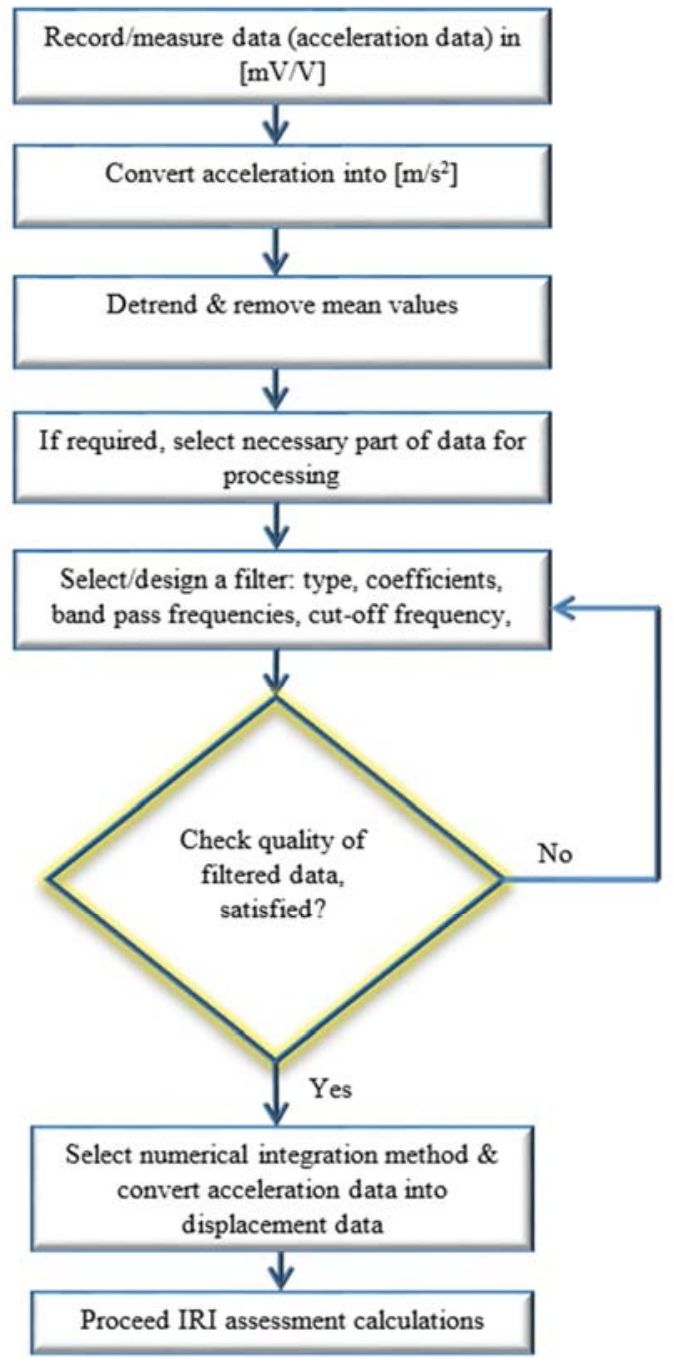

Figure 3. Generalized data analysis procedures.

Two test runs are performed for each driving speeds: 20, $30,40,50,60$ and $70 \mathrm{~km} / \mathrm{h}$ with two sampling frequencies of 500 and $1000 \mathrm{~Hz}$ with single axis accelerometers. Similarly, measurements with a constant speed of $20,30,40,50 \mathrm{~km} / \mathrm{h}$ with Roughometer III (Figure 7) in the same $100 \mathrm{~m}$ road section are carried out. This equipment's acceleration sensor is installed (Figure 7) as recommended in its technical documentations on the shock absorber of the rear axle.

The measured reference points (of the road surface profile) collected with Total Station 06 (Figure 8) are analyzed with the IRI assessments (IRI index plot - Figure 8) and the calculated IRI index is 3.1828. Moreover, all data are detrended, resample and filtered with moving average (Figure 8). The resampled data with $0.1 \mathrm{~m}$ from the measured data has showed IRI index to be 3.35 .

It should be noted that it was aimed to have the constant speeds of the vehicle at $20,30,40,50,60,70 \mathrm{~km} / \mathrm{h}$, but actual speeds have been slower or faster by $5 \ldots 10 \%$. Additionally for comparison purposes, the response type of measurements are carried out with the equipment set of Roughometer III with the constant speed of 20, 30, 40, 50 $\mathrm{km} / \mathrm{h}$ that have showed the automatically computed IRI index values $0.8,3.3,3.1,3.0$, respectively.

The IRI values computed by Roughometer III were not sufficiently stable, for instance at $20 \mathrm{~km} / \mathrm{h}$ IRI index $=2.0$ and at $23 \mathrm{~km} / \mathrm{h}$ IRI index $=2.0$. In addition, it must be noted that the recommended speed range for this equipment is 40 $60 \mathrm{~km} / \mathrm{h}$.

The measured accelerations from the single axis accelerometers on the selected road section at the constant speed of 20, 30, 40, 50, 60, $70 \mathrm{~km} / \mathrm{h}$ have showed (Figure 911) that acceleration magnitudes with $1000 \mathrm{~Hz}$ sampling frequency in higher speeds (Figure 10,11) have gone up more than with $500 \mathrm{~Hz}$. That can be explained with the fact that higher sampling frequency enhances higher noise magnitudes. That can be explained with the vehicle suspension response on the profile irregularities with a higher sensitivity.

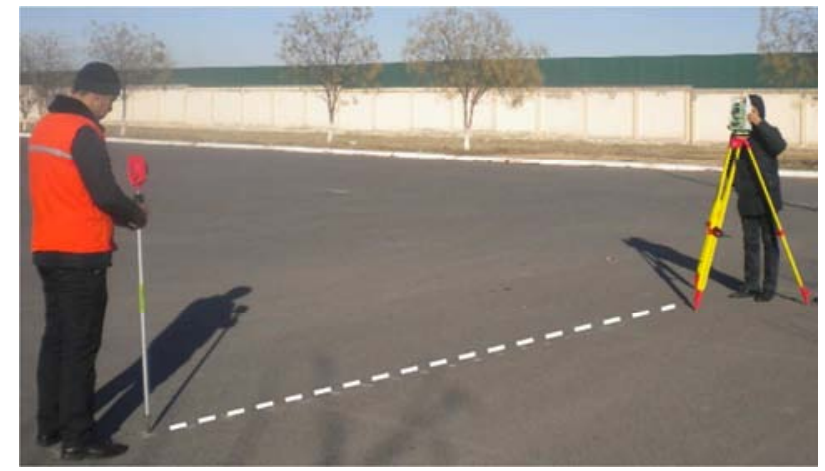

Figure 4. Reference measurements on the selected road segment with total station 06 of Leica Geo-System ${ }^{\text {тм }}$.

The recorded (raw) acceleration data from the single axis accelerometers have gone preliminary quality control checks according to the procedures (Figure 2) in time domain by converting the recorded accelerometer's data from [V] into $\left[\mathrm{m} / \mathrm{s}^{2}\right]$ unit. After removing mean values of the data and detrending them, the data are filtered with the digital filters (Table 1), viz. Low-pass IIR (Butterworth), band-pass (Butterworth), low-pass Chebyshev, moving-average and Low \& high pass FIR filter design by constrained leastsquares filters in order to identify the most fit filter type for processing of raw data. Parameters of these filters (Table 1) are tuned considering the values of the two natural frequencies of the vehicle and how the computed vertical 
displacement values would correlate with the reference IRI index (Figure 8) computed from the road profile measurements obtained with Total Station 06 of Leica GeoSystem $^{\mathrm{TM}}$. In designing digital filters [22], ready to use functions of MATLAB ${ }^{\mathbb{R}}$ are employed directly.

Plots of some selected measured acceleration data at constant speeds of with single axis accelerometers from the two sides of the front axle and car frame are shown in Figure 9-11. After filtering the measurement data for each test run from the single axis accelerometers, vertical displacements on two sides of the front axle and car body (frame) are computed. The displacements are computed by cumulative trapezoidal, trapezoidal, Simpson's methods, and Fourier and inverse Fourier transforms in frequency domain. Also, some numerical analyses are performed how to improve accuracy of the computed vertical displacement values from acceleration data by removing a fit model of each computed data of displacement in time domain. All of the computed vertical displacements from each test run are used to calculate IRI index assessments and plotted against reference IRI index assessment of the road profile data from Total Station 06. Every set of measurement data undergone the initial quality has been filtered with the filters (the parameters given in Table 1) and its IRI index values for right and left side of the front axle are computed. The computed IRI index assessments are grouped for 500 and $1000 \mathrm{~Hz}$ sampling frequencies along with the results computed different integration techniques and used digital filters (Table 2 ). From the performed numerical analyses, it was clear to have $500 \mathrm{~Hz}$ sampling frequency in collecting data that would reduce undesired noises in recorded data, ease filtering of raw data and enhance accuracy of the computed displacement values.

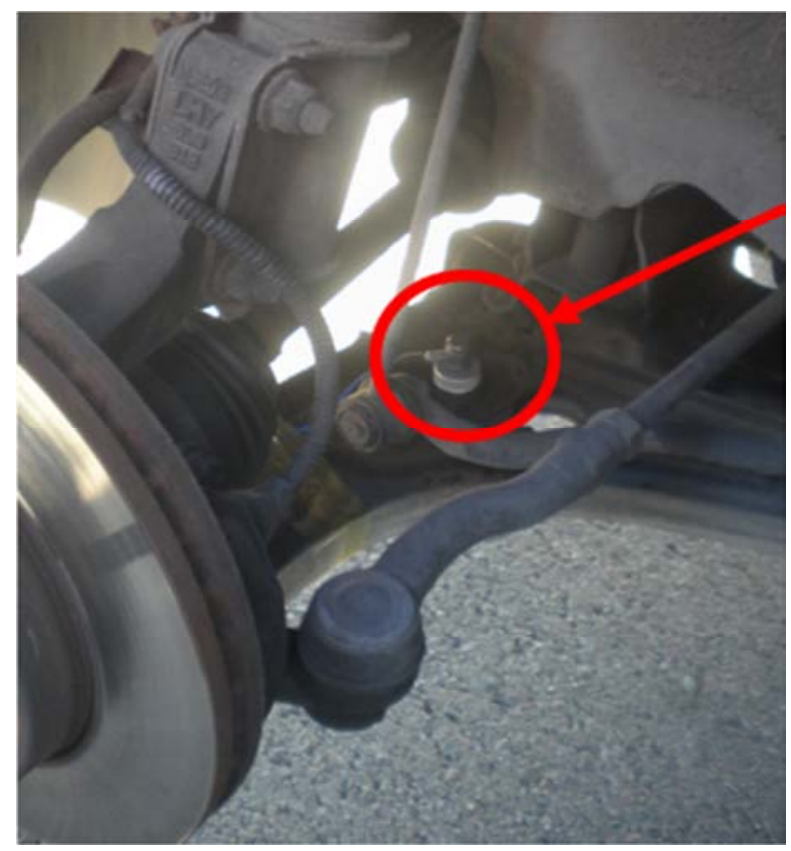

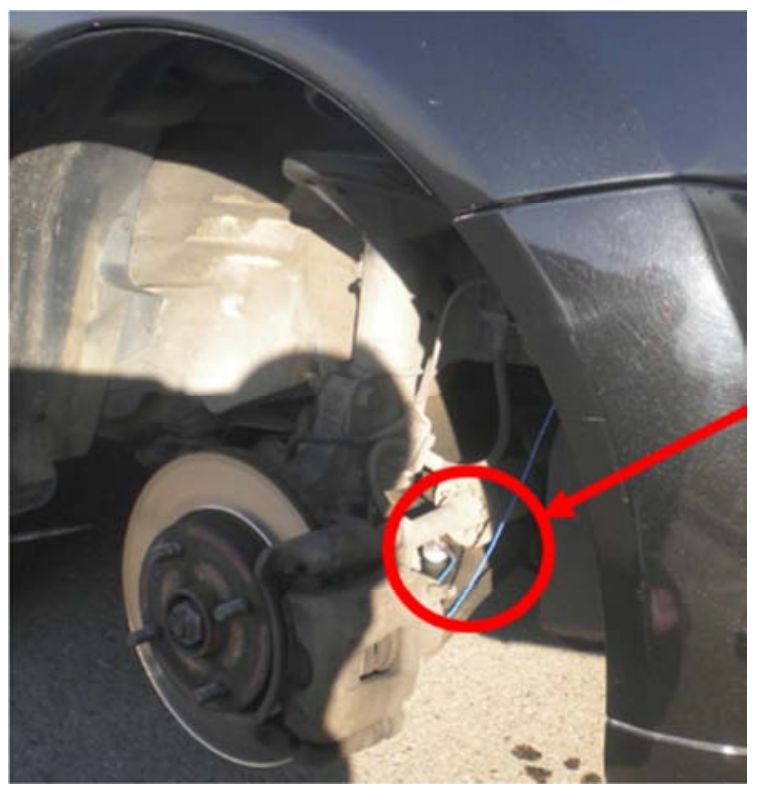

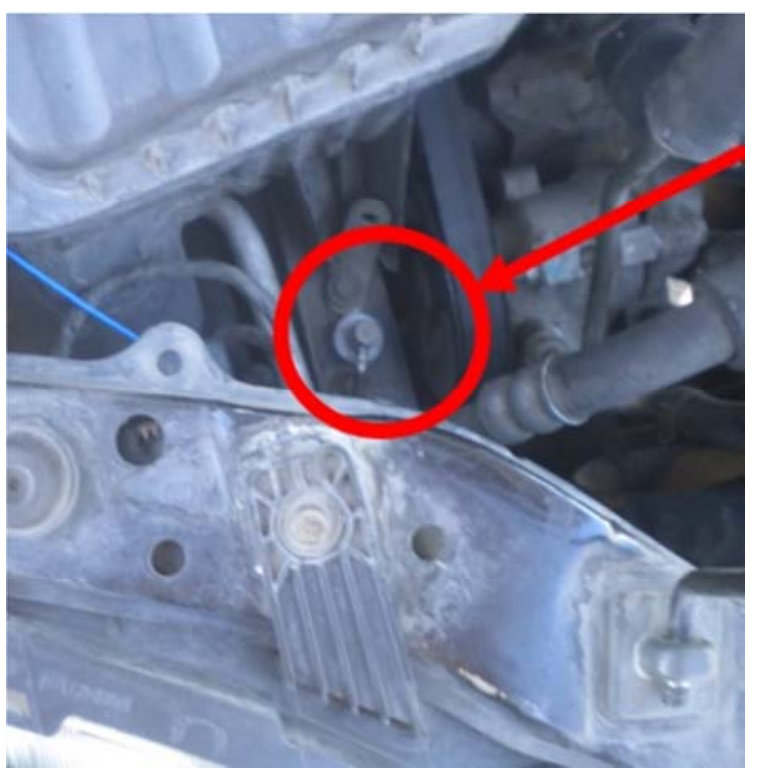

Figure 5. Installation of accelerometers (left side and right side of the axle, and car body) to record road excitations.

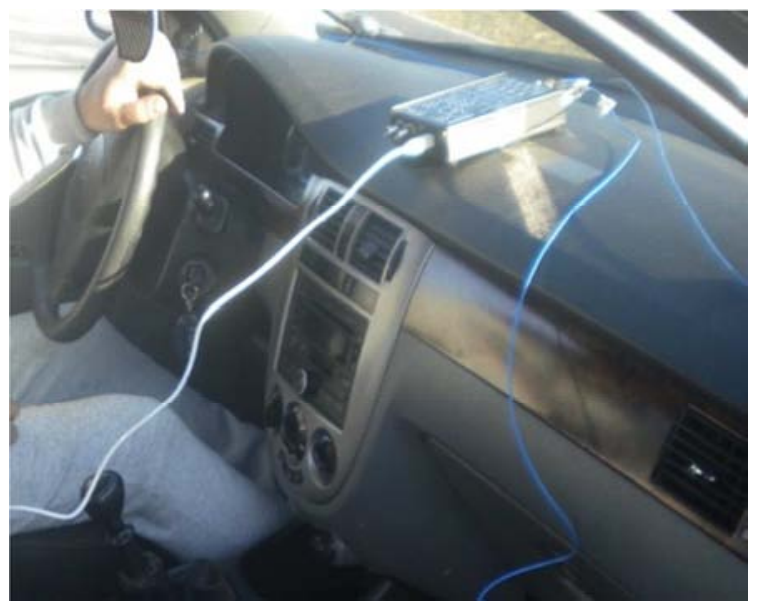



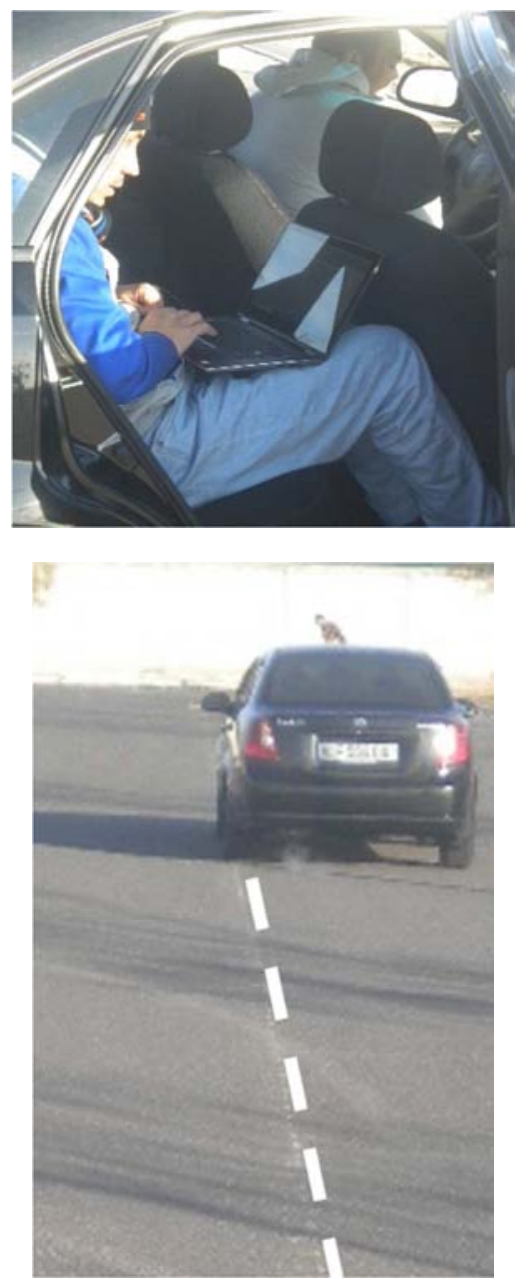

Figure 6. Data collection process from the installed accelerometers (left side and right side of the axle, and car body) to record road profile.
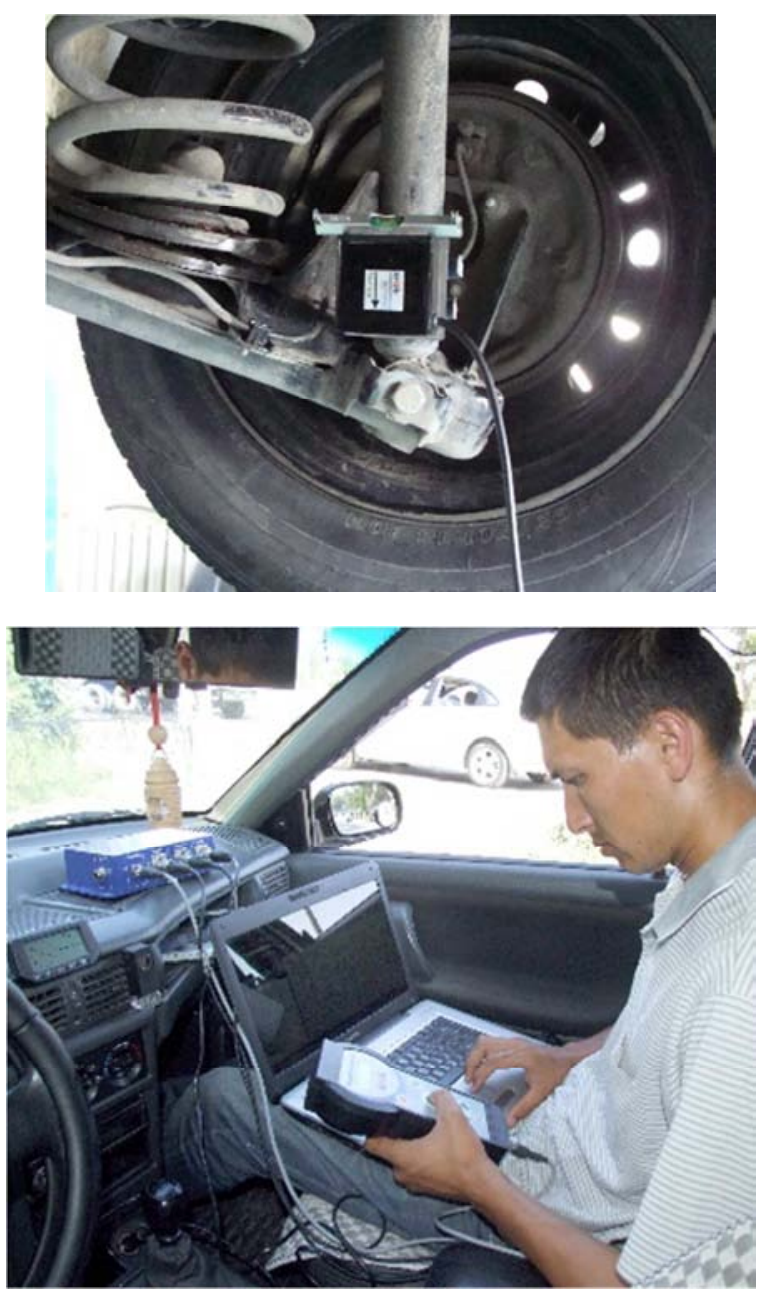

Figure 7. Installation and data collection with roughometer III.

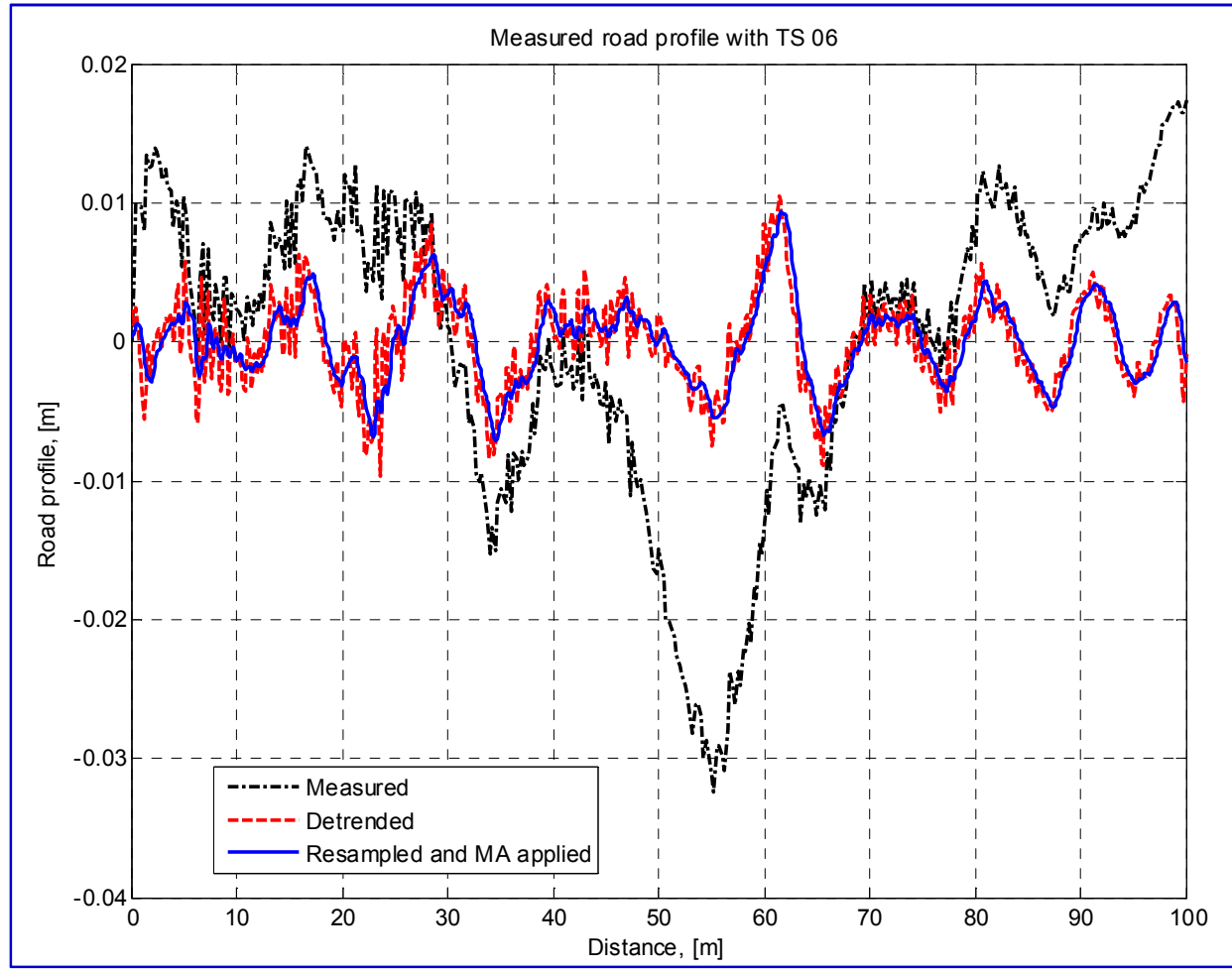




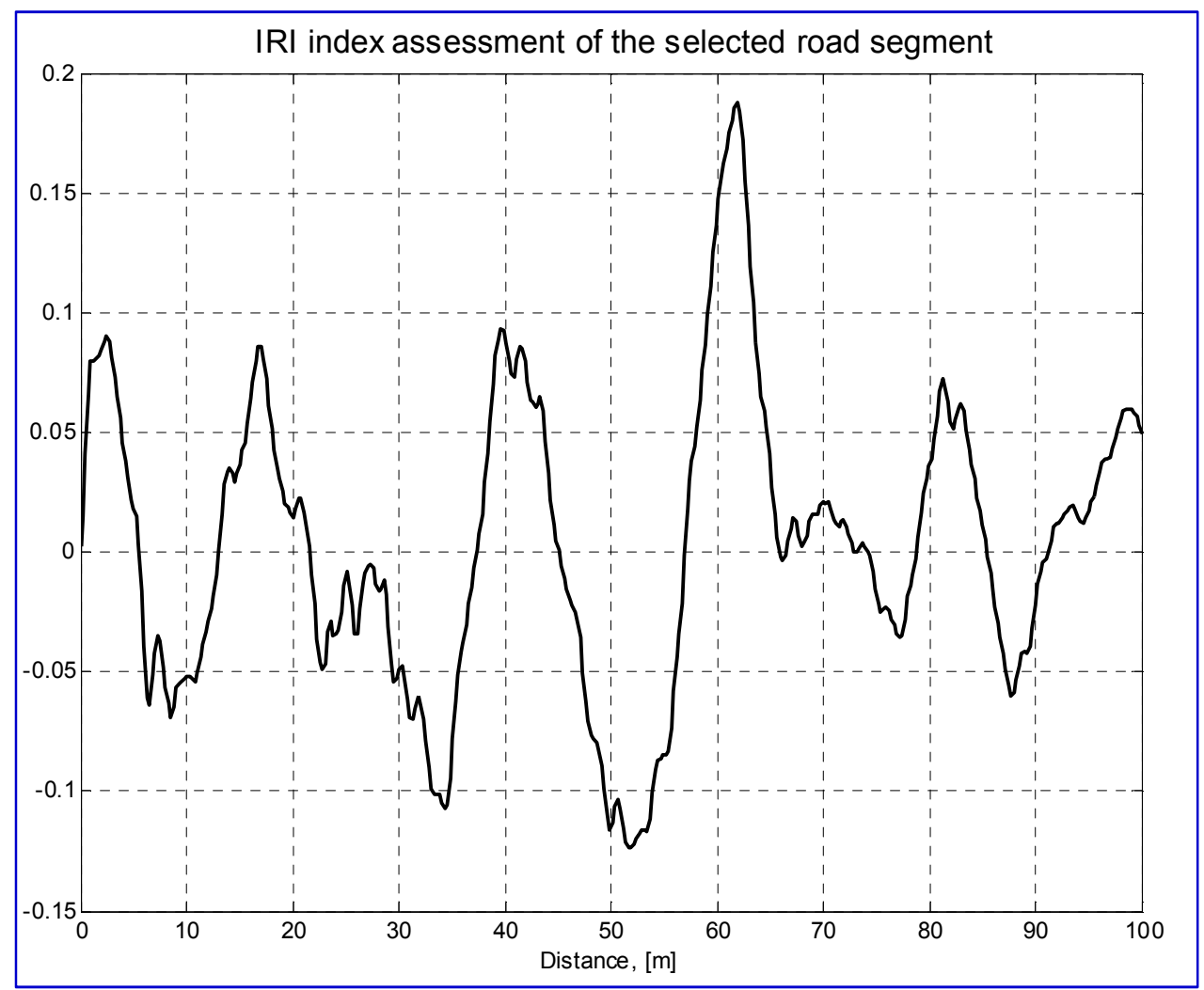

Figure 8. The road profile roughness measured with Total Station 06 on the selected $100 \mathrm{~m}$ road section and its calculated IRI index with the Golden Car.

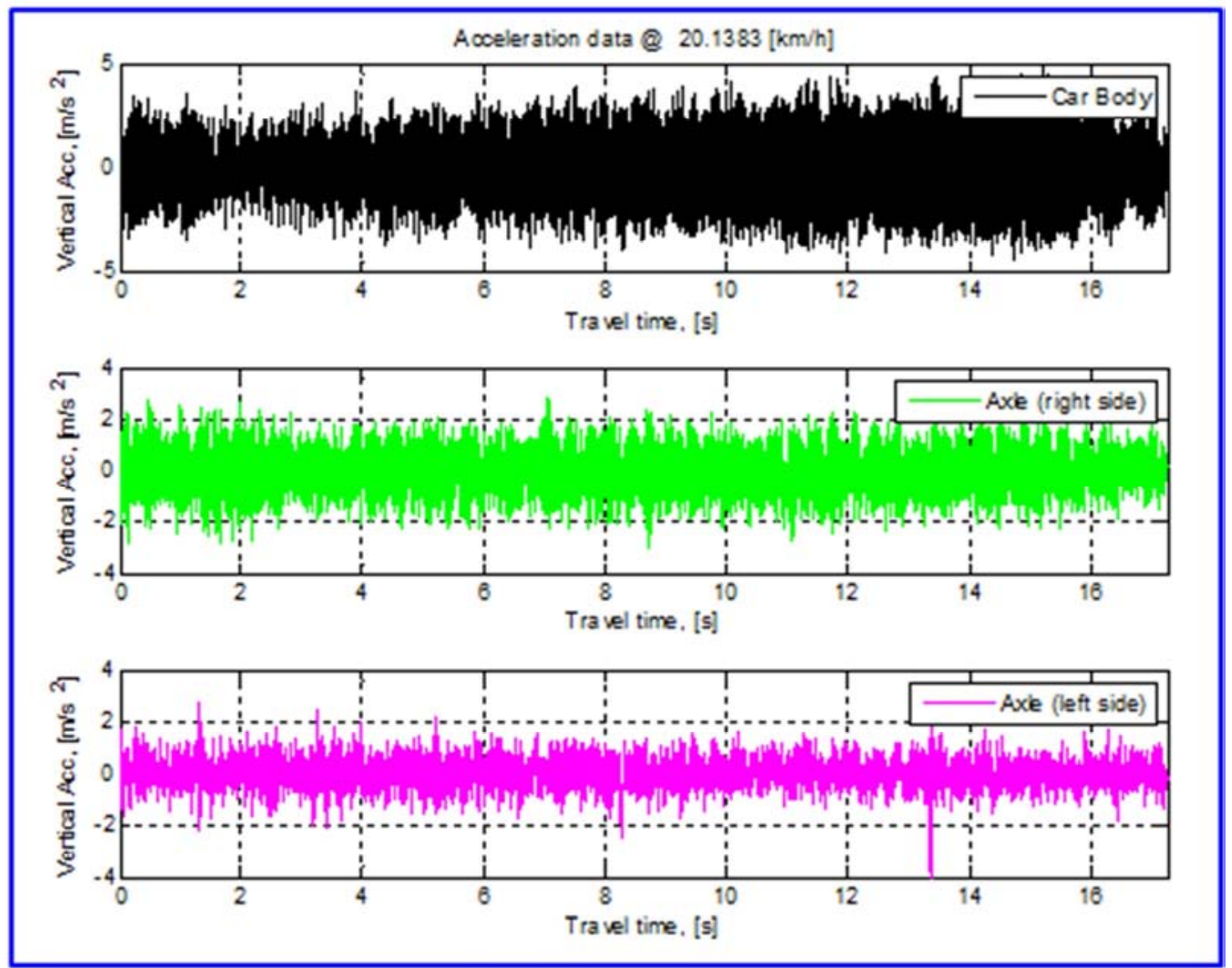




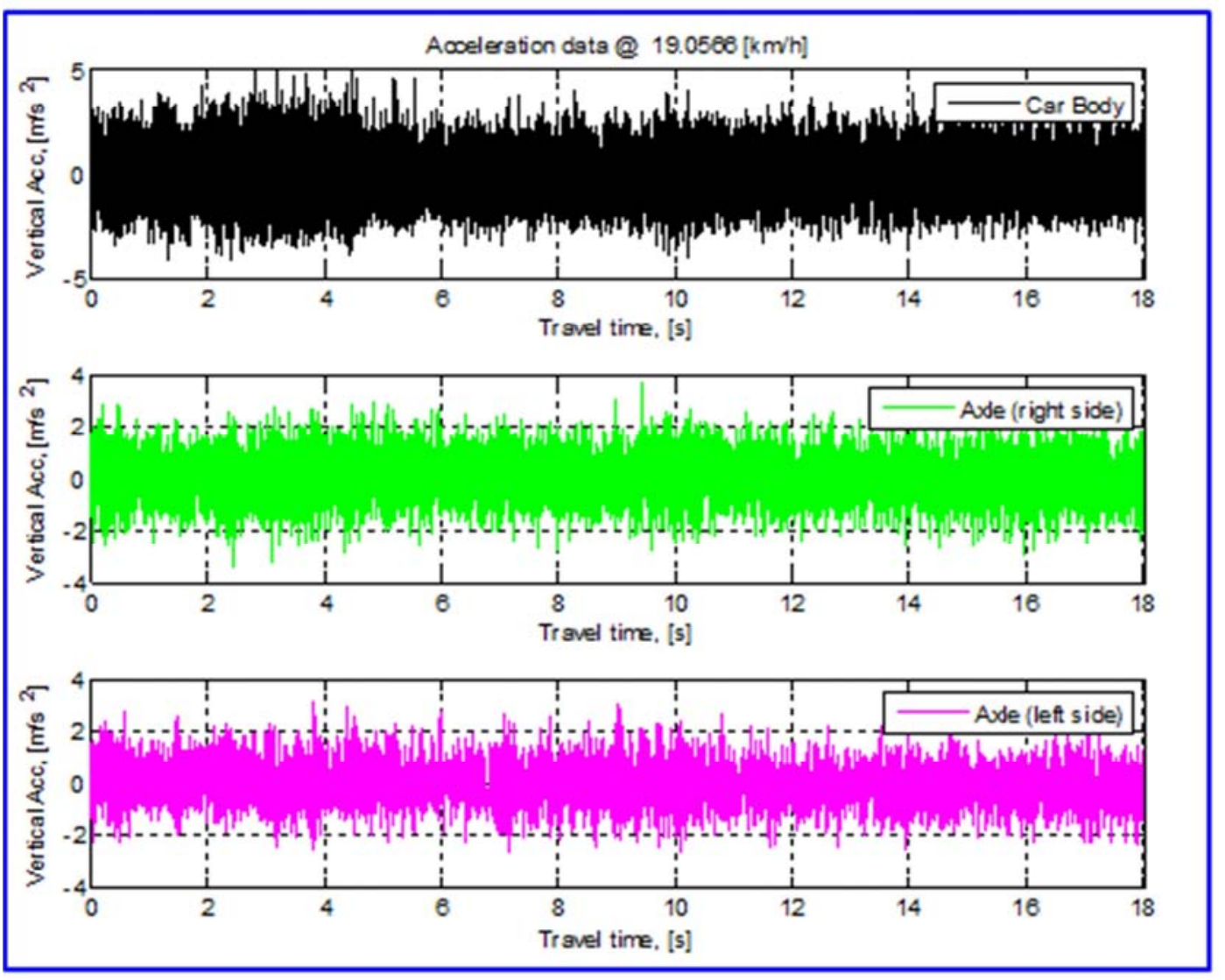

Figure 9. Raw acceleration data collected at $20 \mathrm{~km} / \mathrm{h}$ with sampling frequencies of $500 \mathrm{~Hz}$ and $1000 \mathrm{~Hz}$.

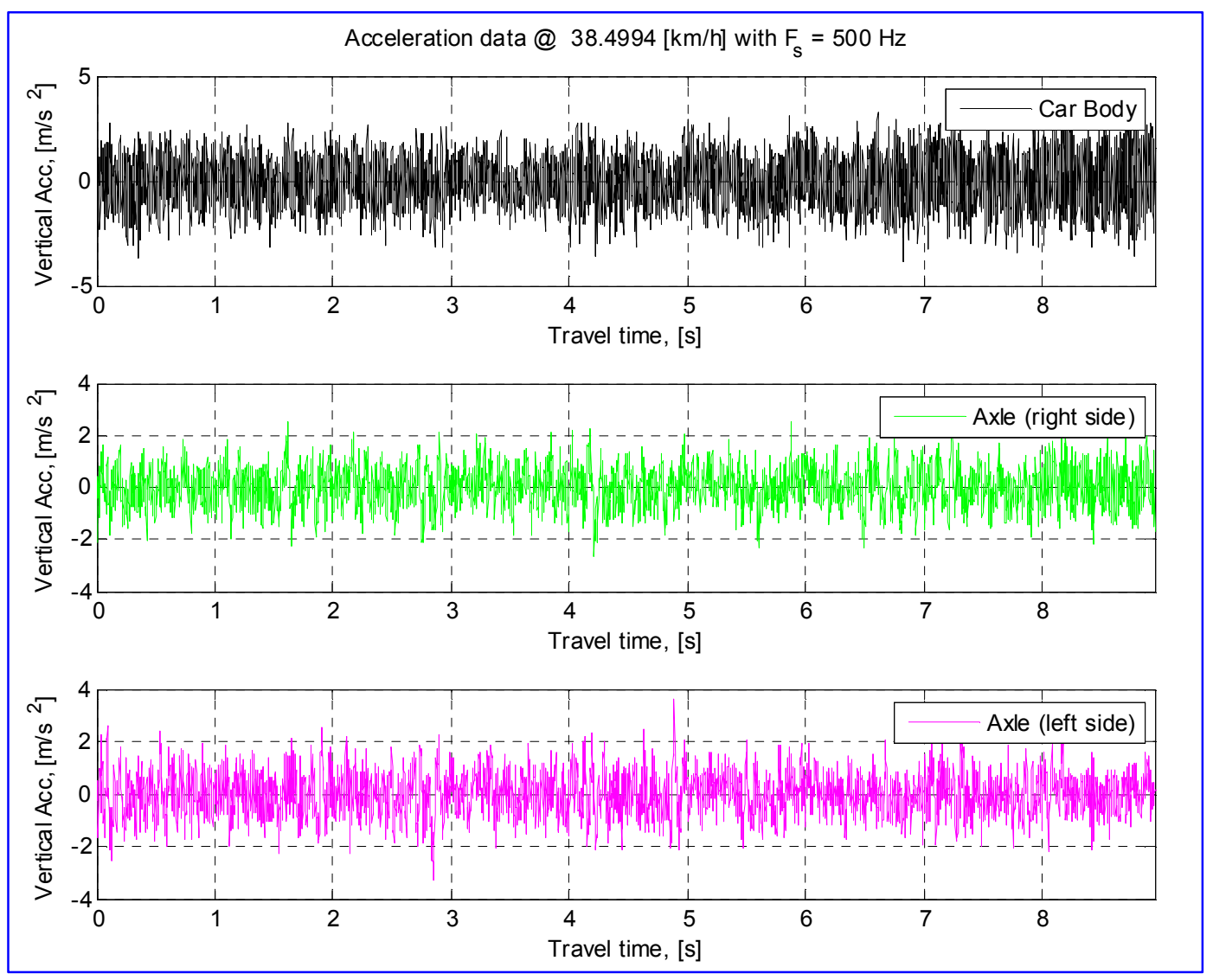




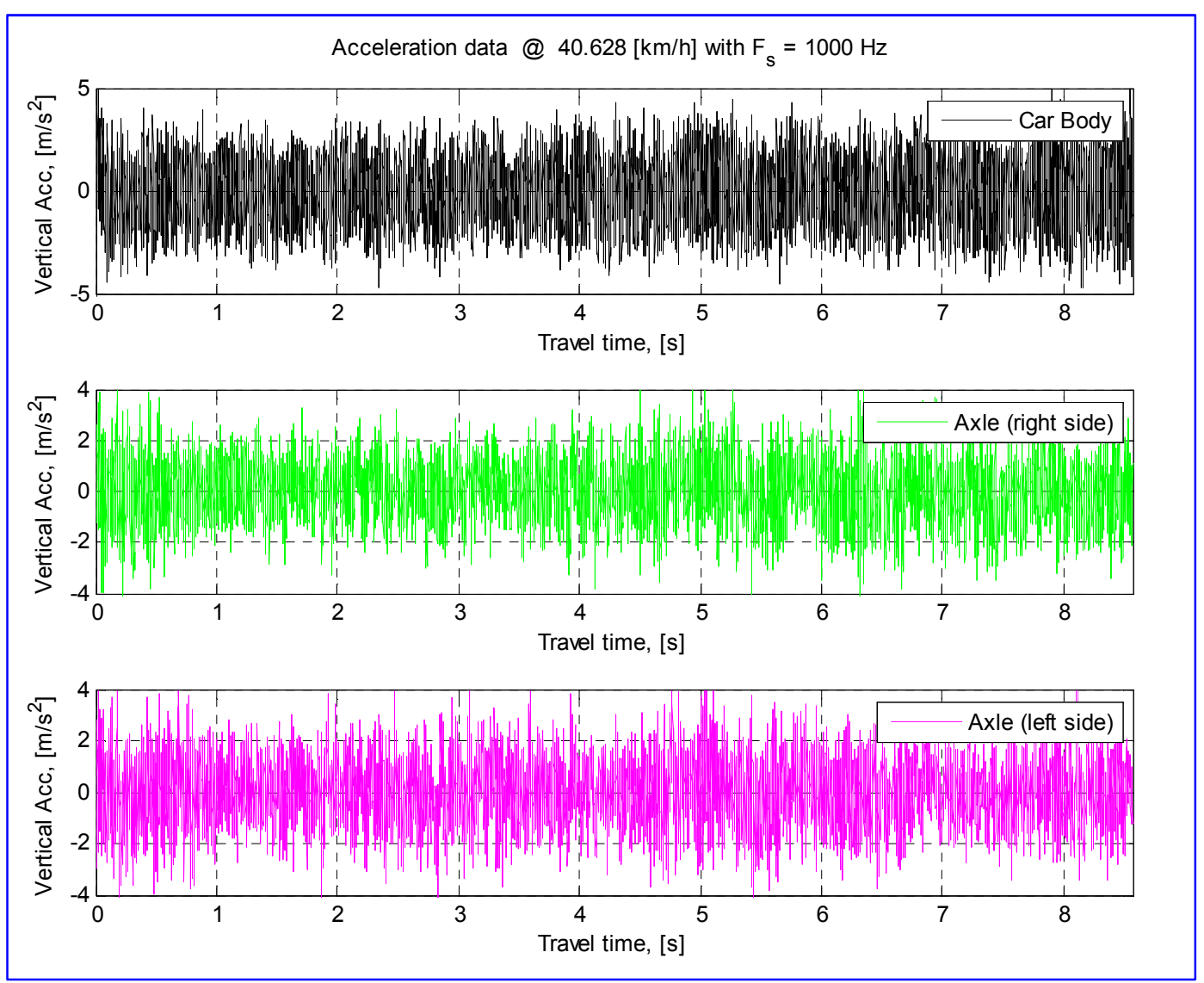

Figure 10. Raw acceleration data collected at the speed of $40 \mathrm{~km} / \mathrm{h}$ with sampling frequencies of 500 and $1000 \mathrm{~Hz}$.

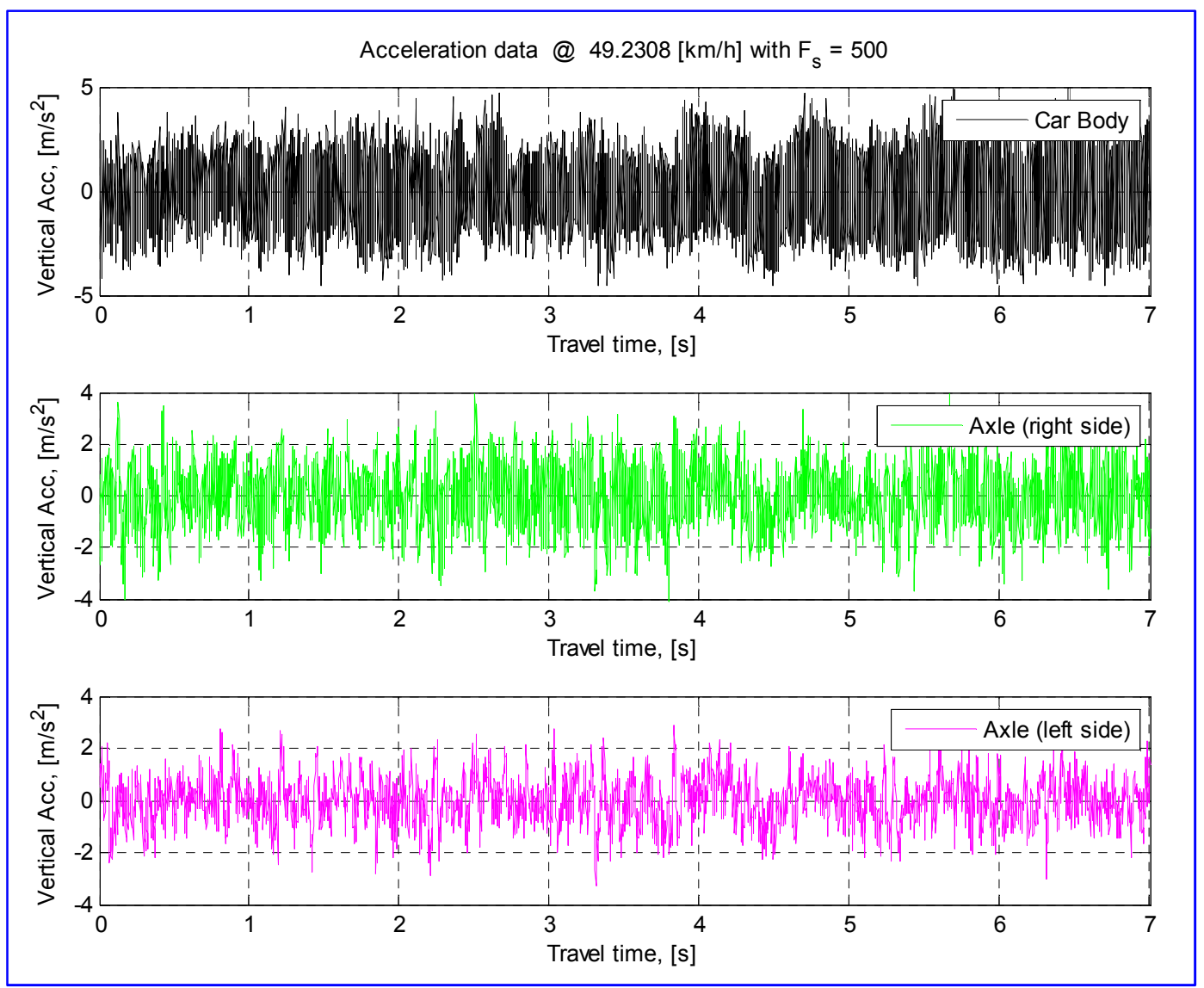




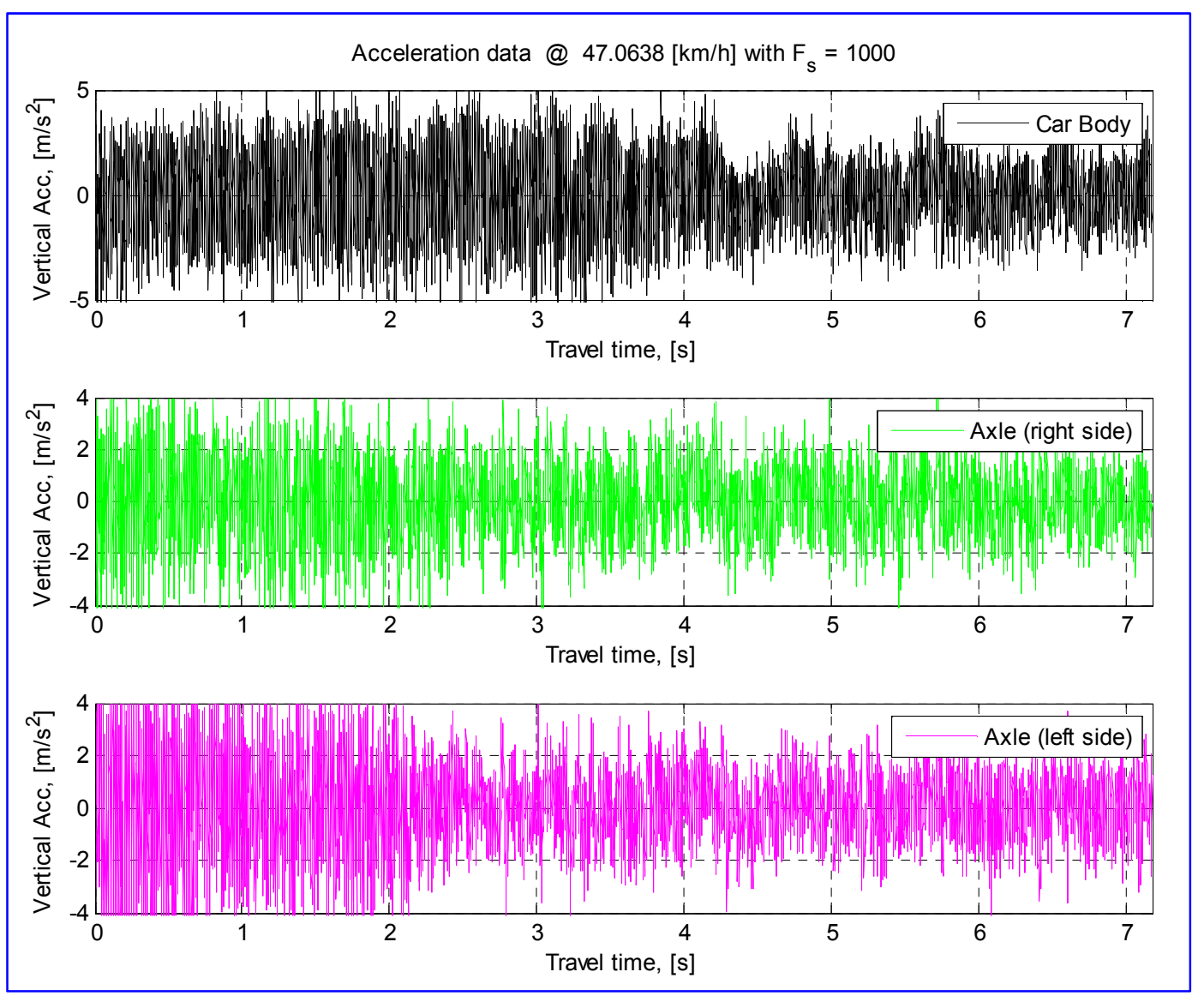

Figure 11. Raw acceleration data collected at the speed of $50 \mathrm{~km} / \mathrm{h}$ with sampling frequencies of 500 and $1000 \mathrm{~Hz}$.

Table 1. Filters and their parameters.

\begin{tabular}{ll}
\hline Filter type & Parameters \\
\hline Low-pass IIR (Butterworth), & Order: 5 \\
& Normalized frequency ratio: 0.025 \\
Band-pass (Butterworth), & Pass frequency bands: $0.5 \mathrm{~Hz}$ and $30 \mathrm{~Hz}$ \\
& Filter order: 2 \\
Low-pass FIR1 (Chebyshev) & Order: 34 \\
& Normalized Frequency ratio: 0.5 \\
& Chebyshev Window: 35,30 \\
& Window Size: 6 \\
Moving-average & Numerator: 2 \\
& Denominator: 6 \\
& Order of the filter: 45 \\
Low \& High pass FIR filter design by constrained & Cut-off frequency of 0.3 (normalized one) \\
& Maximum pass-band deviation from 1 (pass-band ripple) of 0.06. \\
least-squares & Maximum stop-band deviation from 0 (stop-band ripple) of 0.001 \\
\hline
\end{tabular}

Table 2. IRI index assessment calculations from the data measured at different speeds and two different sampling frequencies.

\begin{tabular}{|c|c|c|}
\hline Test \#: speed and sampling frequency & $\begin{array}{l}\text { IRI index }([\mathrm{mm} / \mathrm{m}]) \text { and Filter Type } \\
\text { (for data sampled at } 500 \mathrm{~Hz}) \\
\text { L -left side, } \mathrm{R} \text {-right side of the axle }\end{array}$ & $\begin{array}{l}\text { IRI index and Filter Type } \\
\text { (for data sampled at } 1000 \mathrm{~Hz} \text { ) } \\
\text { L -left side, } \mathrm{R} \text {-right side of the axle }\end{array}$ \\
\hline \multicolumn{3}{|l|}{$20 \mathrm{~km} / \mathrm{h}(500 \mathrm{~Hz}$ and $1000 \mathrm{~Hz}$ frequency): } \\
\hline 1) Cumulative Trapezoidal & 4.797 (L); 39.195 (R): Moving Average & 4.165 (L); 19.829 (R): Low \& High Pass FIR \\
\hline 2) Fourier and inverse Fourier Transforms & 2.777 (L); 2.296 (R): Band-Pass Butter & 4.716 (L); 5.420 (R): Low Pass FIR1 \\
\hline 3) Simpsons' method & 2.785 (L); 2.987 (R): Band-Pass Butter & 2.023 (L); 2.082 (R): Band-Pass Butter \\
\hline 4) Trapezoidal method & 0.240 (L); 0.224 (R): Band-Pass Butter & 2.178 (L); 2.241 (R): Band-Pass Butter \\
\hline \multicolumn{3}{|l|}{$30 \mathrm{~km} / \mathrm{h}(500 \mathrm{~Hz}$ and $1000 \mathrm{~Hz}$ frequency): } \\
\hline 1) Cumulative Trapezoidal & 2.954 (L); 3.305 (R): Band-Pass Butter & 2.420 (L); 2.327 (R): Band-Pass Butter \\
\hline 2) Fourier and inverse Fourier Transforms & 2.259 (L); 2.267 (R): Band-Pass Butter & 15.124 (L); 7.965 (R): Low Pass FIR1 \\
\hline
\end{tabular}




\begin{tabular}{|c|c|c|}
\hline Test \#: speed and sampling frequency & $\begin{array}{l}\text { IRI index }([\mathrm{mm} / \mathrm{m}]) \text { and Filter Type } \\
\text { (for data sampled at } 500 \mathrm{~Hz} \text { ) } \\
\text { L -left side, R -right side of the axle }\end{array}$ & $\begin{array}{l}\text { IRI index and Filter Type } \\
\text { (for data sampled at } 1000 \mathrm{~Hz} \text { ) } \\
\text { L -left side, R -right side of the axle }\end{array}$ \\
\hline 3) Simpsons' method & 2.241 (L); 2.256 (R): Low \& High Pass FIR & 2.395 (L); 2.343 (R): Band-Pass Butter \\
\hline 4) Trapezoidal method & 2.937 (L); 4.753 (R): Low Pass FIR1 & 3.682 (L); 3.203 (R): Low Pass FIR1 \\
\hline \multicolumn{3}{|l|}{$40 \mathrm{~km} / \mathrm{h}(500 \mathrm{~Hz}$ and $1000 \mathrm{~Hz}$ frequency): } \\
\hline 1) Cumulative Trapezoidal & 1.996 (L); 2.191 (R): Low \& High Pass FIR & 2.615 (L); 36.009 (R): Moving Average \\
\hline 2) Fourier and inverse Fourier Transforms & 2.501 (L); 2.227 (R): Band-Pass Butter & 2.264 (L); 2.542 (R): Band-Pass Butter \\
\hline 3) Simpsons' method & 2.072 (L); 2.188 (R): Band-Pass Butter & 2.110 (L); 2.281 (R): Band-Pass Butter \\
\hline 4) Trapezoidal method & 0.899 (L); 3.097 (R): Low Pass FIR1 & 0.693 (L); 3.906 (R); Low Pass FIR1 \\
\hline \multicolumn{3}{|l|}{$50 \mathrm{~km} / \mathrm{h}(500 \mathrm{~Hz}$ and $1000 \mathrm{~Hz}$ frequency): } \\
\hline 1) Cumulative Trapezoidal & 2.908 (L); 3.356 (R): Low Pass Butter IIR & 8.588 (L); 7.909 (R): Moving Average \\
\hline 2) Fourier and inverse Fourier Transforms & 3.900 (L); 2.881 (R): Low Pass FIR1 & 4.296 (L); 3.628 (R): Low Pass FIR1 \\
\hline 3) Simpsons' method & 2.798 (L); 2.774 (R): Band-Pass Butter & 2.408 (L); 2.597 (R): Band-Pass Butter \\
\hline 4) Trapezoidal method & 1.517 (L); 2.032 (R): Low Pass FIR1 & 2.751 (L); 1.754 (R): Low Pass FIR1 \\
\hline \multicolumn{3}{|l|}{$60 \mathrm{~km} / \mathrm{h}(500 \mathrm{~Hz}$ and $1000 \mathrm{~Hz}$ frequency): } \\
\hline 1) Cumulative Trapezoidal & 3.255 (L); 6.672 (R): Low \& High Pass FIR & 4.008 (L); 3.215 (R): Low Pass FIR1 \\
\hline 2) Fourier and inverse Fourier Transforms & 3.147 (L); 3.781 (R): Moving Average & 3.038 (L); 2.924 (R): Band-Pass Butter; \\
\hline 3) Simpsons' method & 2.667 (L); 2.760 (R): Band-Pass Butter & 3.040 (L); 2.912 (R): Band-Pass Butter \\
\hline 4) Trapezoidal method & 1.771 (L); 1.968 (R): Band-Pass Butter & 2.266 (L); 1.534 (R): Low Pass FIR1 \\
\hline \multicolumn{3}{|l|}{$70 \mathrm{~km} / \mathrm{h}(500 \mathrm{~Hz}$ and $1000 \mathrm{~Hz}$ frequency): } \\
\hline 1) Cumulative Trapezoidal & 3.215 (L); 14.059 (R): Low Pass IIR & 2.744 (L); 2.663 (R): Band-Pass Butter \\
\hline 2) Fourier and inverse Fourier Transforms & 0.601 (L); 0.419 (R): Low Pass IIR & 3.074 (L); 3.526 (R): Low Pass IIR \\
\hline 3) Simpsons' method & 2.492 (L); 3.636 (R): Band-Pass Butter & 2.730 (L); 2.651 (R): Band-Pass Butter \\
\hline 4) Trapezoidal method & 0.175 (L); 0.183 (R): Band-Pass Butter & 2.590 (L); 2.730 (R): Low Pass FIR1 \\
\hline 5) Newmark- $\beta$ method & 2.990 (L); 3.081 (R): Band-Pass Butter & -- \\
\hline
\end{tabular}

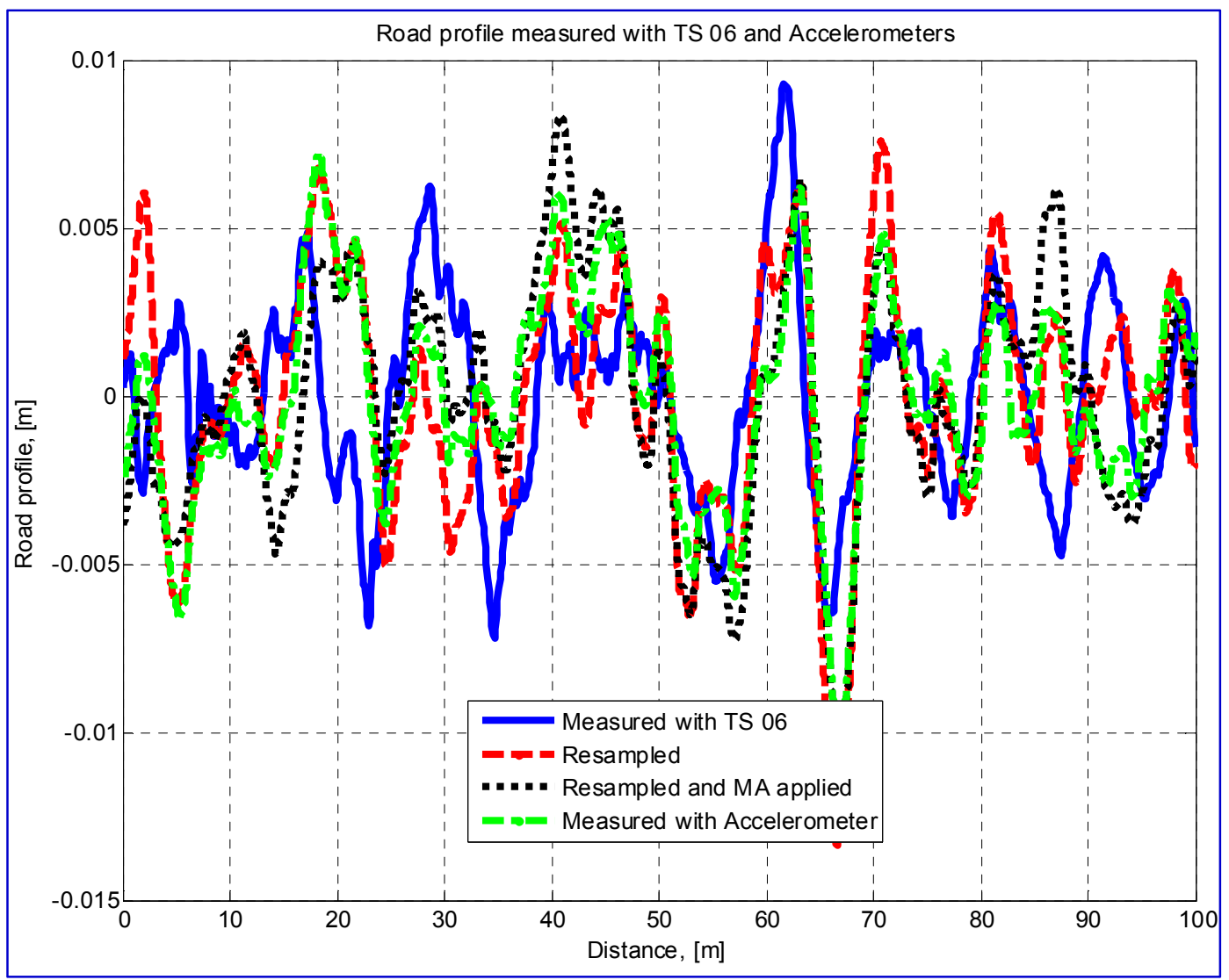




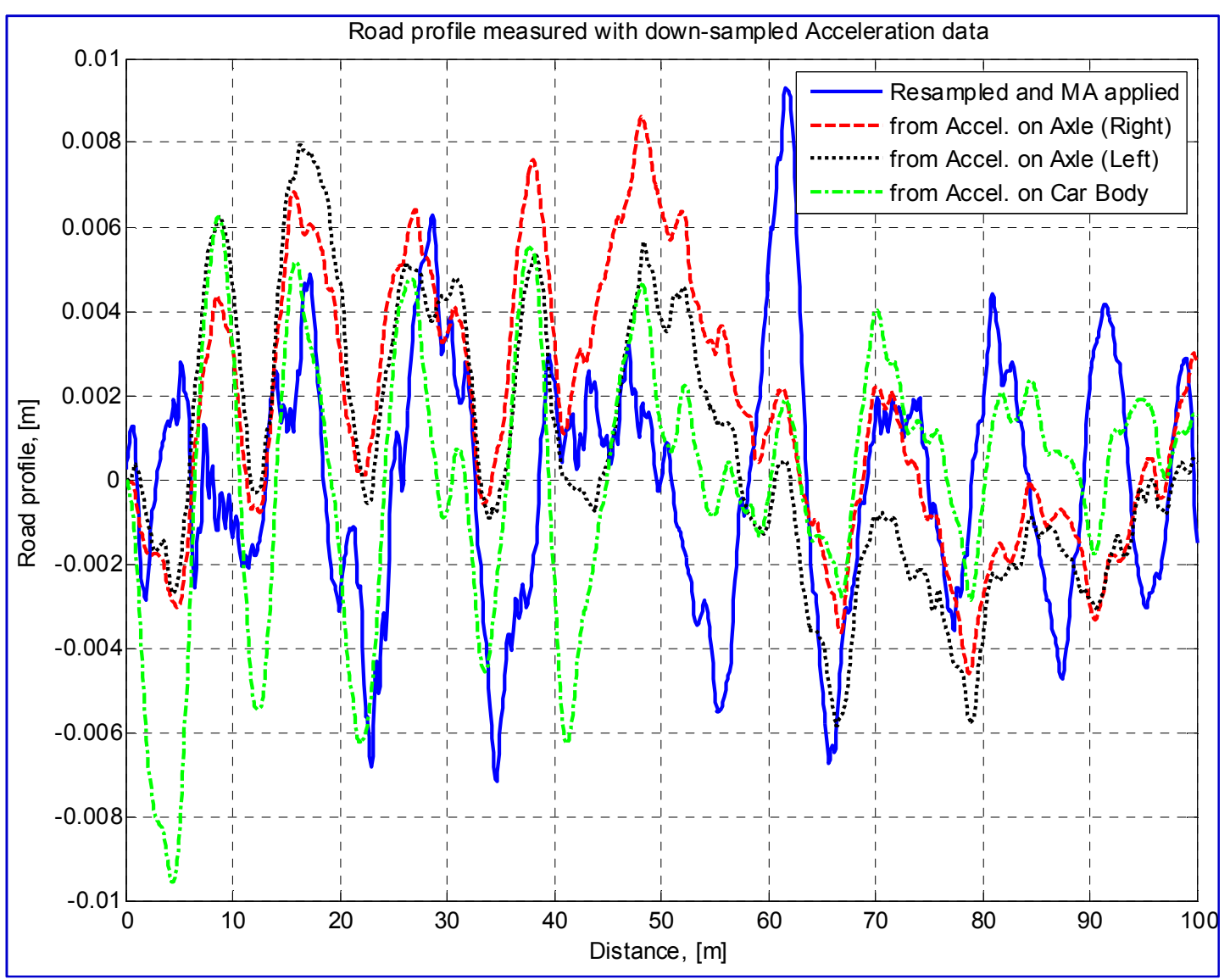

Figure 12. Data measured at $20 \mathrm{~km} / \mathrm{h}$ and $30 \mathrm{~km} / \mathrm{h}$, road profile data (collected at $500 \mathrm{~Hz}$ and down-sampled at $50 \mathrm{~Hz}$ ) computed with Newmark-beta method and Band-pass filter.

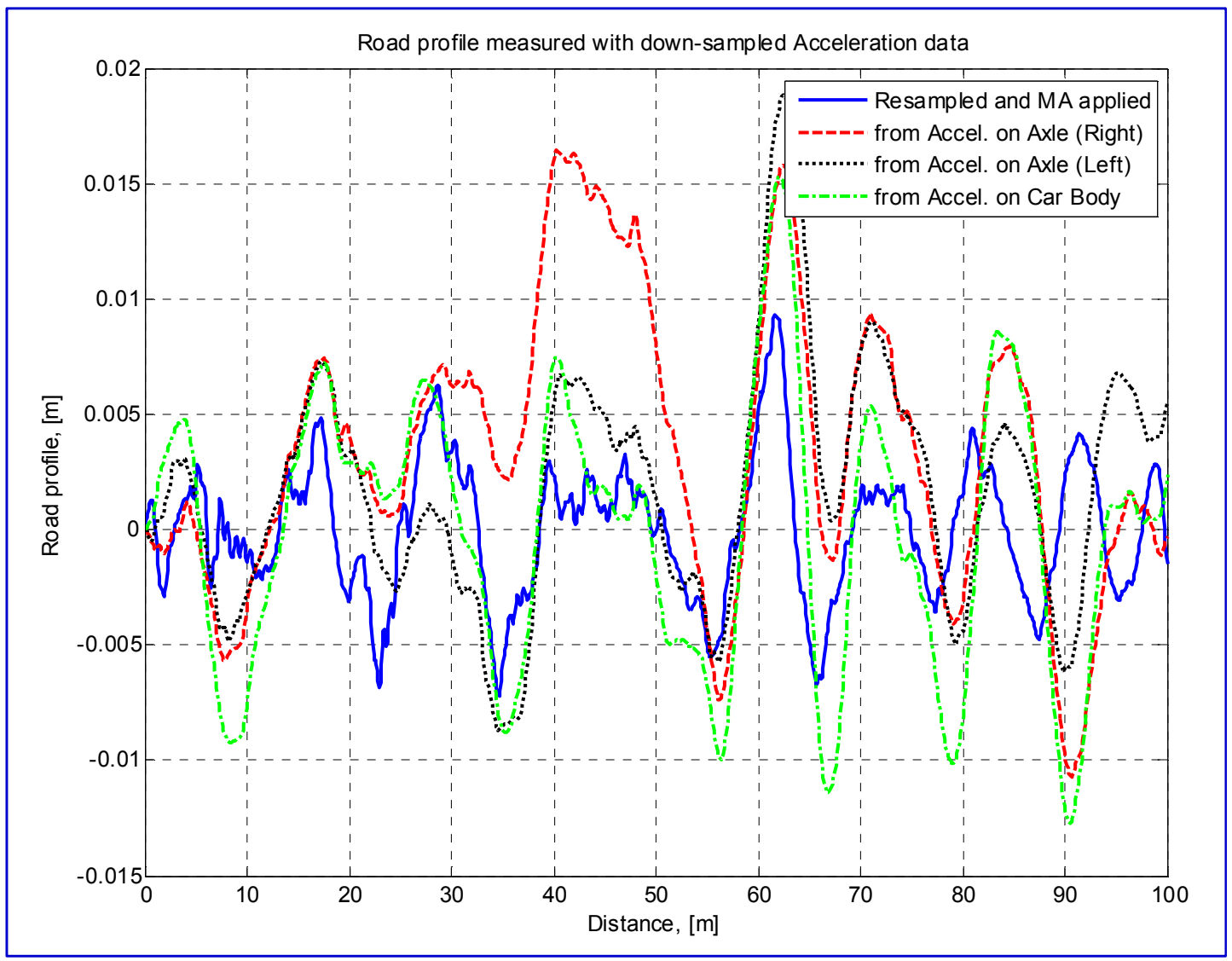




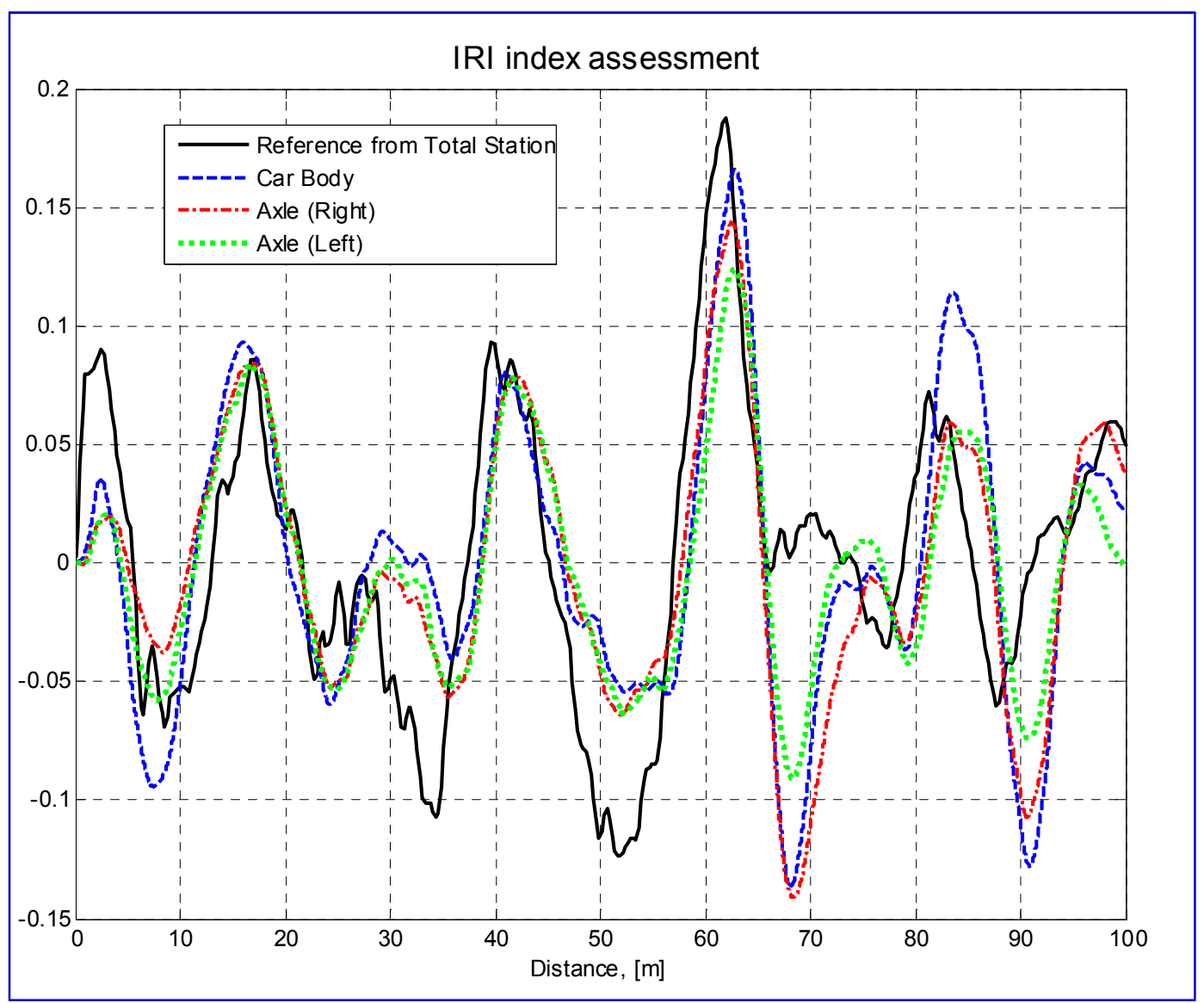

Figure 13. At $40 \mathrm{~km} / \mathrm{h}$, road profile data (collected at $500 \mathrm{~Hz}$ and down-sampled at $50 \mathrm{~Hz}$ ) computed with Newmark-beta method, and filtered with Band-pass filter and IRI assessment of the computed profile.

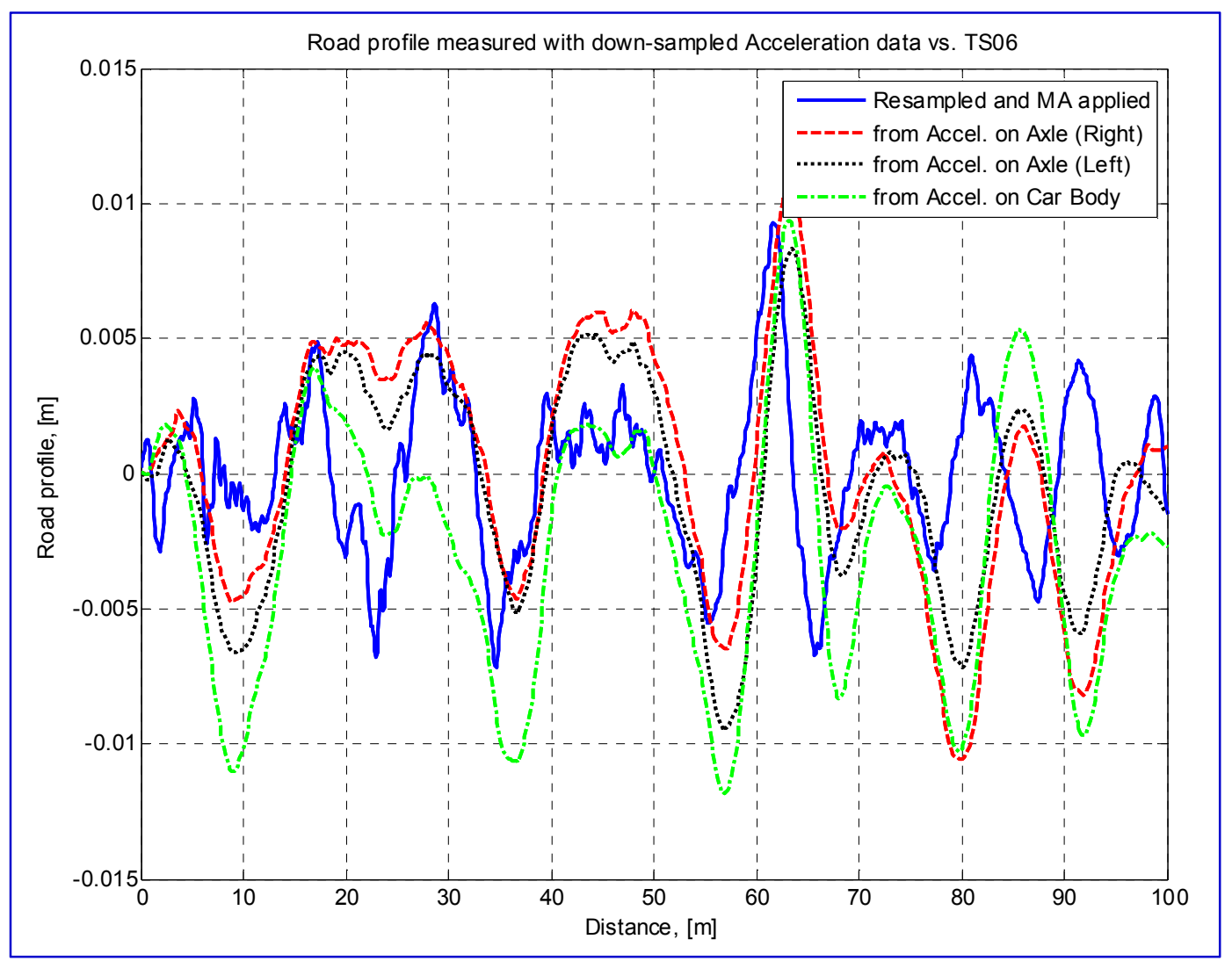




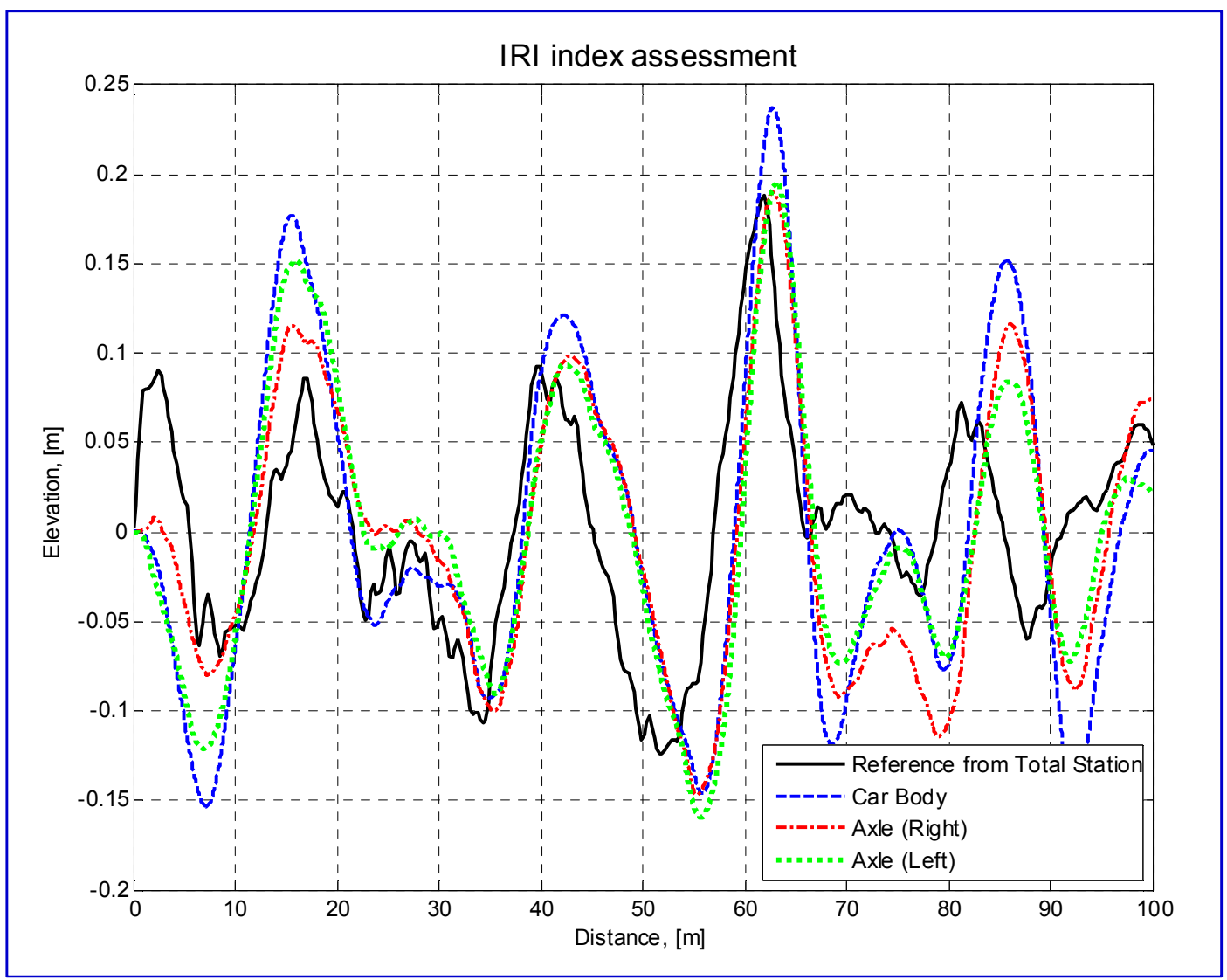

Figure 14. At $50 \mathrm{~km} / \mathrm{h}$, vertical displacement data $\left(f_{s}=500 \mathrm{~Hz}\right)$ computed with Newmark- $\beta$ method and Band-pass filter, and IRI assessment of profile computed with Simpsons method.

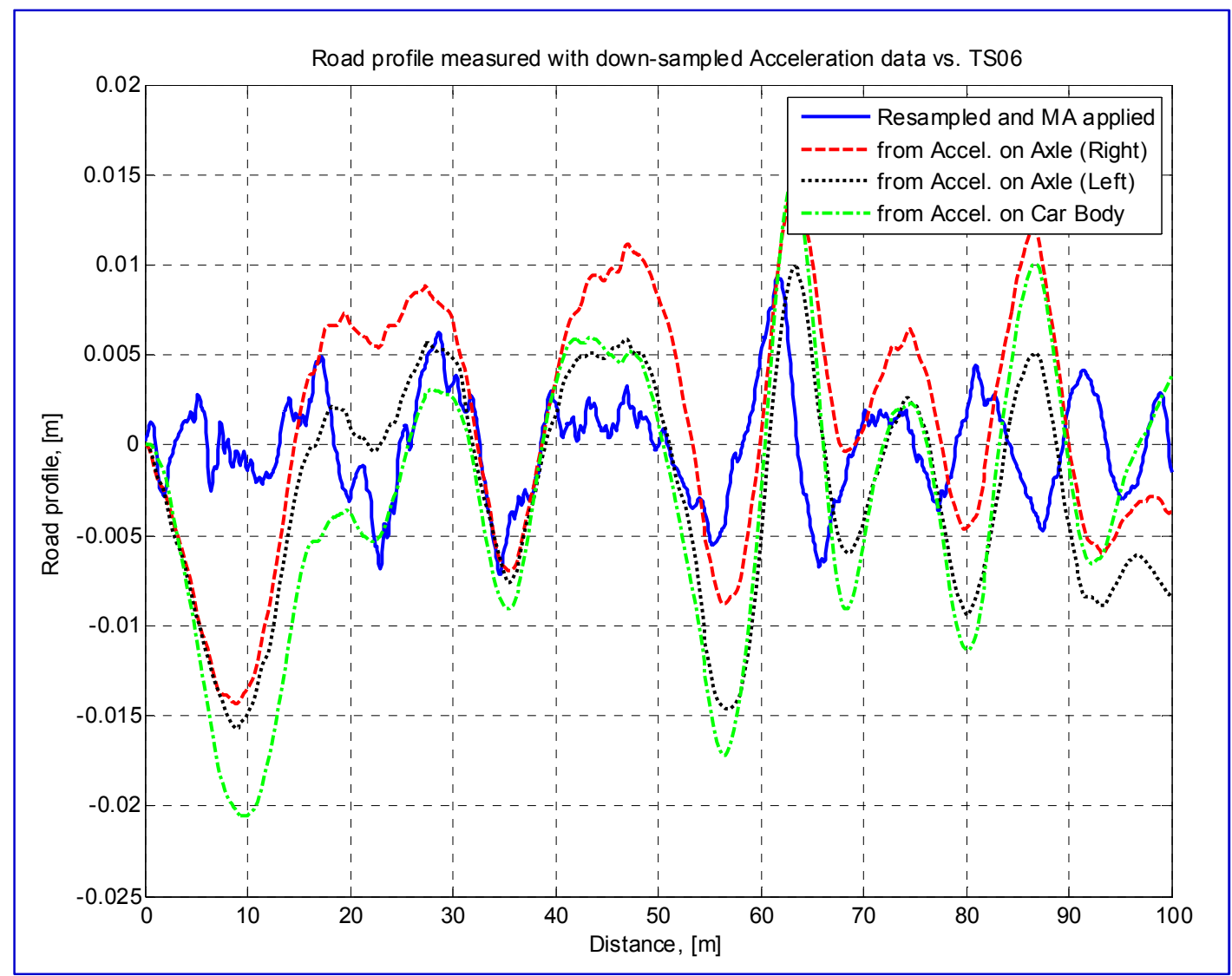




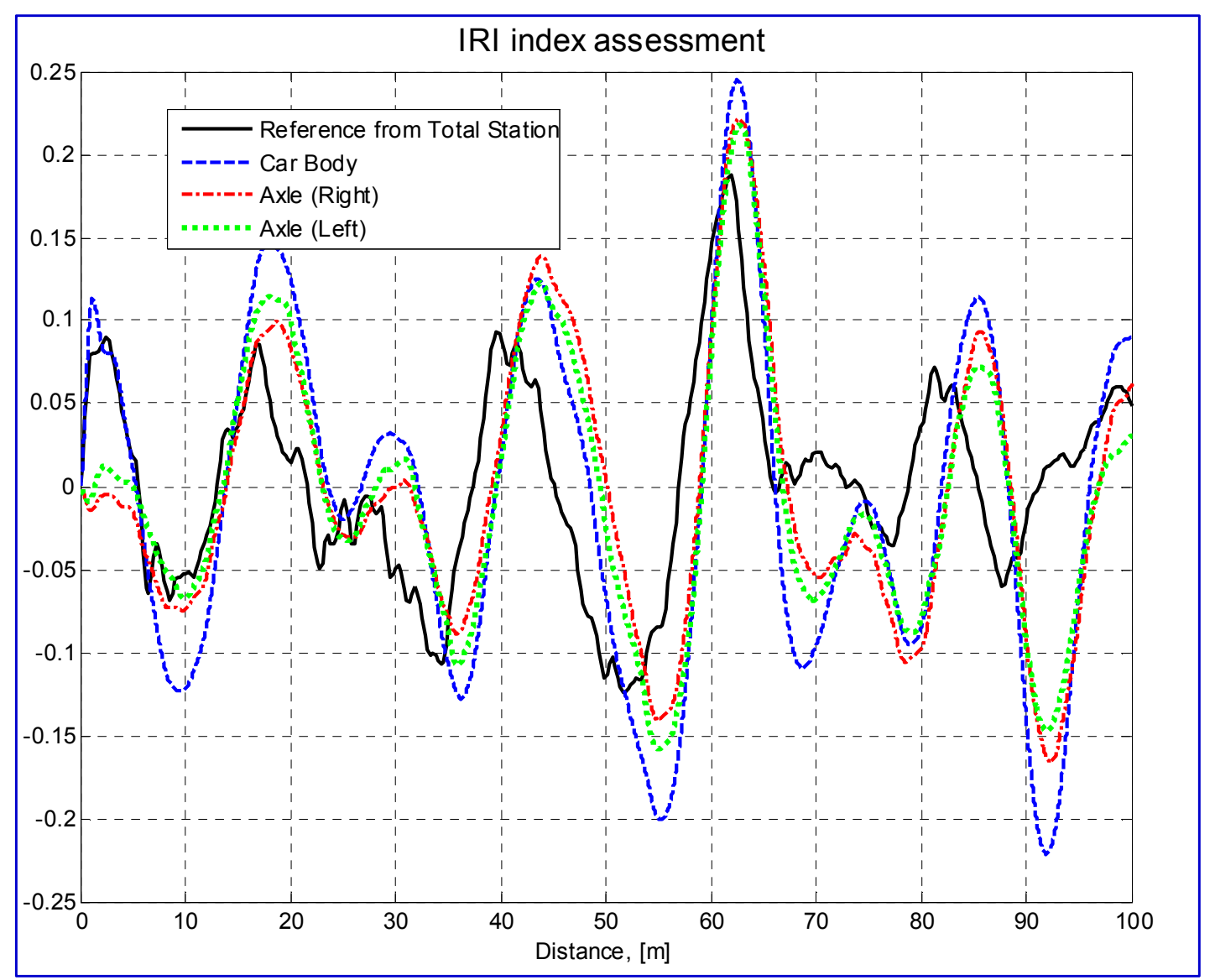

Figure 15. At $60 \mathrm{~km} / \mathrm{h}$, road profile data $\left(f_{\mathrm{s}}=1000 \mathrm{~Hz}\right)$ computed with Newmark- $\beta$ method and IRI assessment of the computed profile computed with Fourier and inverse Fourier transform methods and band-pass filter used.

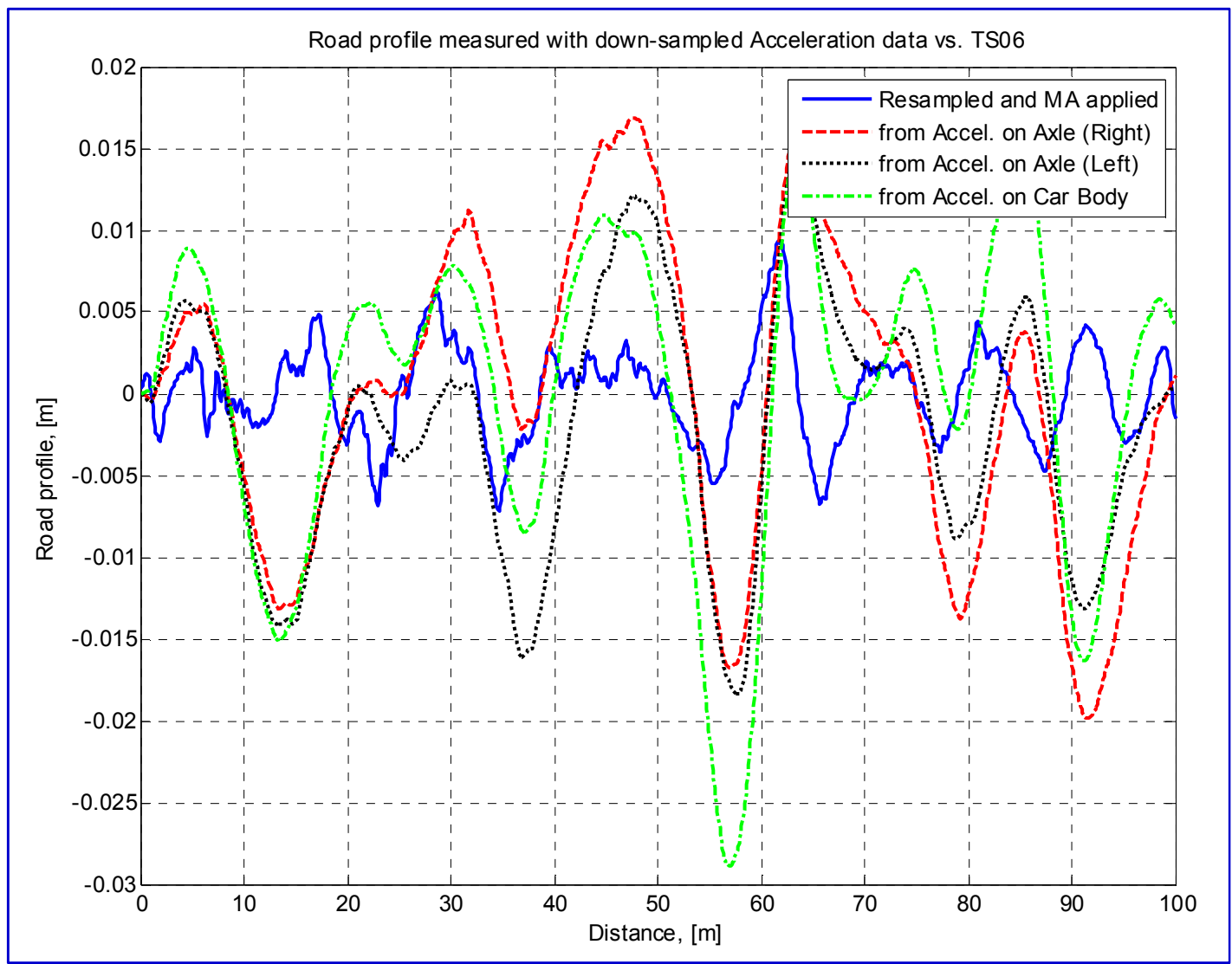




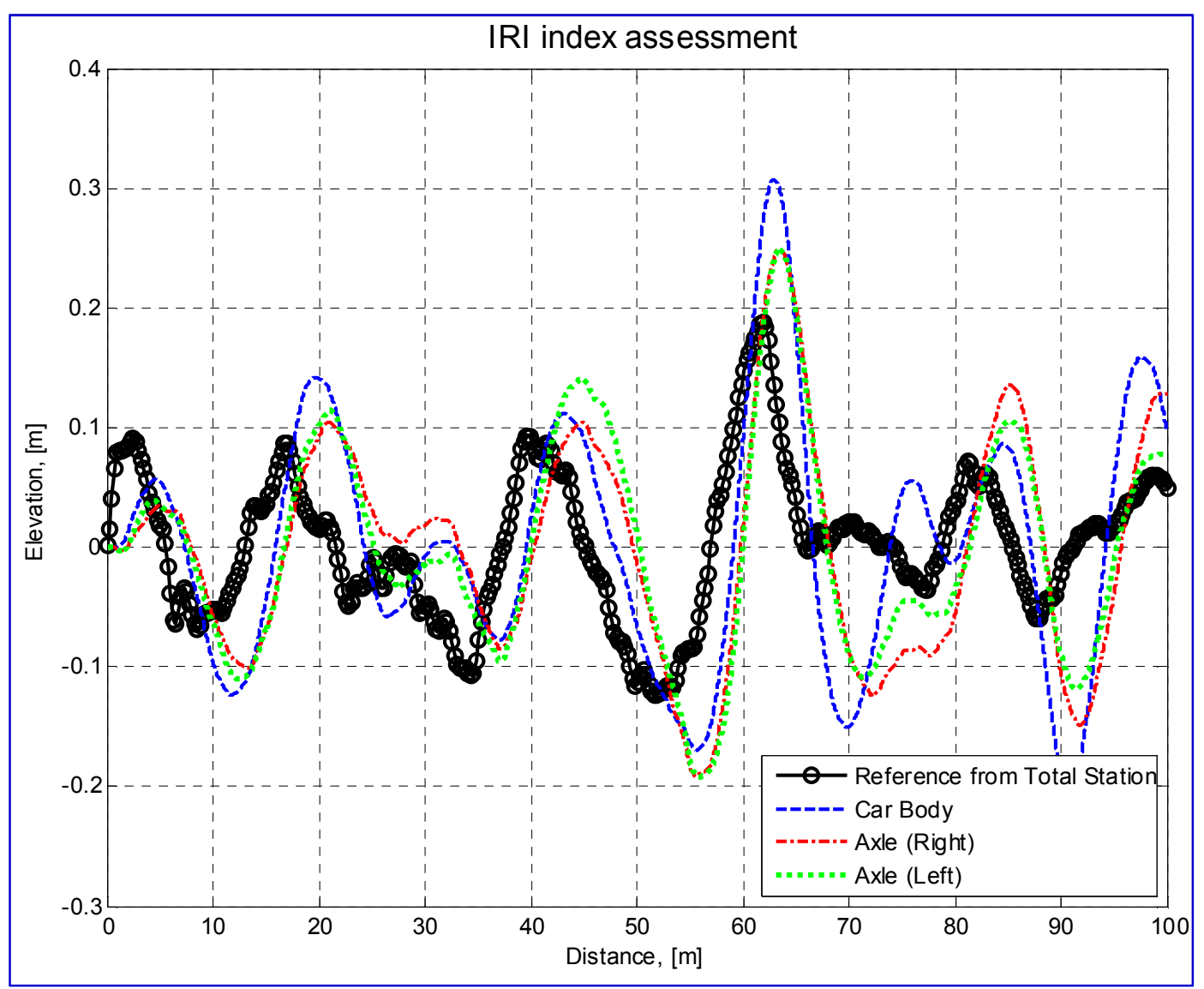

Figure 16. At $70 \mathrm{~km} / \mathrm{h}$, vertical displacement data $\left(f_{s}=500 \mathrm{~Hz}\right)$ and IRI assessment of the computed road profile with Newmark- $\beta$ method and Band-pass filter.

From the measured acceleration data at different speeds and computed vertical displacement sets, and calculated IRI index assessments, it is clear that in lower speeds (20 and 30 $\mathrm{km} / \mathrm{h}$ ), there is a convergence of the computed road profile shown in Figure 12 with the measured reference profile as shown in Figure 8, but the convergence is with some deviations. On the other hand, at higher speeds $-40,50$ and $60 \mathrm{~km} / \mathrm{h}$, the convergence of the measured profiles shown in Figure 13, 14, 15 computed with Newmark- $\beta$ method with respect to the reference profile are considerably better than the data measured at about $70 \mathrm{~km} / \mathrm{h}$ as shown in Figure 16 . Similar observations shown in Figure 13, 14, 15 are obtained with IRI index assessments of the computed road profile data. It should be noted that keeping up a constant speed at higher speeds, like $70 \mathrm{~km} / \mathrm{h}$ was not feasible for the whole distance of $100 \mathrm{~m}$. Moreover, it is observed that the computed vertical displacements of car axle (measured on the right and left sides) and body are well correlated in-between.

Moreover, it is observed that the measurements with the single access accelerometers in lower vehicle speeds $(20,30$ $\mathrm{km} / \mathrm{h}$ ) are much higher in accuracy than the measurements obtained from Roughometer III that has some considerable limitations and can only give overall IRI assessment. Whereas, this response type of measurements with accelerometers can give a possibility to measure road profile with certain accuracy along with the IRI index assessment at different speeds. From the studies, it is observed that data sampling will influence on the quality of the measured data and its processing with filters. Furthermore, it is salient to be careful in selecting the right digital filtering technique and the appropriate integration method. Amongst tested and tuned digital filters Band-Pass Butterworth filter has showed to be more appropriate than any other filters studied in the numerical simulations. Newmark- $\beta$ method is the most appropriate method in computing road profiles with higher accuracy than other studied methods. In the contexts of the paper, it is not shown the obtained fit model with higher order polynomial that has been removed from the measured road profile data.

\section{Conclusions}

The performed studies and measurements on the selected asphalt pavement road in a special road experimental area have demonstrated that measuring road profile roughness with the single axis accelerometers is relatively simple and easy to use technique with a higher precision in assessing road profile with less efforts and small technical skills. It is quite simple to calibrate the hardware tools. However, while employing this approach a user has to be well aware of the fact of careful selection of integration method in computing vertical displacement from the acceleration data. Moreover, it is salient to choose appropriate type of digital filter with well-tuned parameters that influence the quality of data 
processing. From the performed studies, it is advisable to carry out such studies on a constant speed of around $60 \mathrm{~km} / \mathrm{h}$ for roads with asphalt pavement. It should be also noted that an adequate speed value may be increased or decreased depending on the class of the road pavement. The quality of the data filtered with any of the studied filters in this research can be improved further by computing a fit model and removing fit model data from the displacement data substantially. It is recommended to employ a Butter-worth band-pass filter with the frequency bands of 0.5 to $30 \mathrm{~Hz}$, and filter order of 2 .

The measurement technique with accelerometers can be considered as a second class type of equipment for assessing and measuring road profiles due to its precision that can be attained by selecting appropriate digital filter and integration method. Another advantage of this technique with employed tools is cost efficient in comparison with conventional measurement tools of class type II. From the studies, it is clear that by using this approach other profile assessment methods such as power spectral density of road roughness, half-car or full-car model approaches can be also applied. It is advisable to employ this method with accelerometers in assessing newly constructed road pavement profiles. The further studies will be dedicated to investigate how to compute power spectral density of road profiles by using accelerometers and assess not only the quality of the pavement but also its level of degradation including potholes.

\section{Acknowledgements}

Part of this research is supported by the state grant \# A-354 from the State Science and Technology Committee of Uzbekistan and Dynamics \& Control Lab.

\section{References}

[1] M. W. Sayers, "On the Calculation of International Roughness Index from Longitudinal Road Profile," Transportation Research Record: Journal of Transportation Research Board 1501, 1995, pp. 1-12.

[2] ISO 8608 (1995) Mechanical vibration, road surface profiles. Reporting of Measured Data.

[3] S. A. Oke, et al. "Mathematical Modeling of the Road Bumps using Laplace Transform," International Journal of Science \& Technology, Volume 2, No 2, pp. 129-141, 2007.

[4] M. Doumiati, A. Victorio, A. Chara, D. Lechner, "Estimation of Road Profile for Vehicle Dynamics Motion: Experimental Validation," 2011 American Control Conference, San Francisco, CA, USA, pp. 5237-5242.

[5] J. G. Howe, J. P. Chrstos, R. W. Allen, T. T. Mayers, D. Lee, D. J. Gorsich, A. A. Reid, "Quarter car model stress analysis for terrain/road profile ratings," Int. J. Vehicle Design, 26: 248 $-269,2004$.

[6] Y. Du, Ch. Liu, D. Wu, Sh. Jiang, "Measurement of International Roughness Index by Using Z-axis Accelerometers and GPS," Mathematical Problems in
Engineering, Volume 2014, Article ID 928980, http://dxdoi.org/10.1155/2014/928980.

[7] M. W. Sayers., "Two quarter car models for defining road roughness IRI and HRI," Transportation Research Record (1989), 1215, pp. 1-26.

[8] R. A. Capuruco, T. Hegazy, S. L. Tighe, et.al. "Full-car roughness index as summary roughness statistic," Transportation Research Record (2005), 1905, pp. 148-156.

[9] ASTM E 1489-98, 2003. Practice for Computing Ride Number of Roads from Longitudinal Profile Measurements made by an Inertial Profile Measuring Device. ASTM International, West Conshohocken.

[10] M. Agostinacchio, D. Ciampa, S. Olita, "The vibrations induced by surface irregularities in road pavements - a Matlab® Approach”, Springer, Eur. Transp. Res. Rev. (2014) 6: pp. 267 - 275, DOI 10.1007/s12544-013-0127-8.

[11] C. J. Doods and J. D. Robson, "The description of road surface roughness," Journal of Sound and Vibration, 31:175183, 1973.

[12] K. Bogsjo, K. Podgorski, and I. Rychlik, "Models for road sourface roughness," Vehicle System Dynamics, 50:725-747, 2012.

[13] B. Bruscella, V. Rouillard, and M. Sek. "Analysis of road surface profiles," ASCE Journal of Transportation Engineering, 125:55-59, 1999.

[14] M. W. Sayers, S. M. Karamihas, "Interpretation of Road Roughness Profile Data." 1996, Federal Highway Administration.

[15] A. Ueckermann, B. Steinauer, "The Weighted Longitudinal Profile. A new Method to Evaluate the Longitudinal Evenness of Roads," Road Materials and Pavement Design, Volume 9 No. 2/2008, pp. 135-157.

[16] A. Ueckermann, M. Oeser, "Approaches for a 3D assessment of pavement evenness data based on $3 \mathrm{D}$ vehicle models," Science Direct, Journal of Traffic and Transportation Engineering (2nd Edition), 2015: 2 (2): 6880.

[17] M. W. Sayers (1990), Profiles of Roughness. Transportation Research Record, No 1260. Pp. 06-111.

[18] N. M. Newmark, (1959) A method of computation for structural dynamics. Journal of Engineering Mechanics, ASCE, 85 (EM3) 67-94.

[19] T. D. Gillespie, M. W. Sayers, and L. Segel, "Calibration of Response-Type Road Roughness Measuring Systems." Journal: National Cooperative Highway Research Program Report. No. 228, (December, 1980).

[20] S. Eshkabilov, "Modeling and Simulation of Non-Linear and Hysteresis Behavior of Magneto-Rheological Dampers in the Example of Quarter-Car Model," Engineering Mathematics 2016, 1(1): 19-38, Science Publishing, USA (2016).

[21] ASTM Standard E1364-95 (Re-approved-2000). Standard Test for method for measuring road roughness by static level method. ASTM International, 100 Bar Harbor Drive, West Conshohocken, PA, USA.

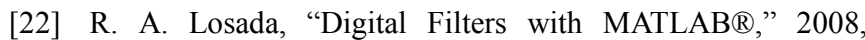
https://www.mathworks.com/tagteam/82961_digfilt.pdf. Viewed: 13.11.2017. 